\title{
When and How to End Shelter-In-Place Protection From a Release of Airborne Hazardous Material: Report on a Decision-Making Concept and Methodology
}

\author{
Report prepared by the \\ Decision and Information Sciences Division \\ Argonne National Laboratory
}

Report prepared for

The Federal Emergency Management Agency

Readiness, Response and Recovery Directorate

July 30, 2001

Argonne National Laboratory, with facilities in the states of Illinois and Idaho, is owned by the United States Government and operated by The University of Chicago under the provisions of a contract with the Department of Energy. 


\section{Disclaimer}

This report was prepared as an account of work sponsored by an agency of the United States Government. Neither the United States Government nor any agency thereof, nor The University of Chicago, nor any of their employees or officers, makes any warranty, expressed or implied, or assumes any legal liability or responsibility for the accuracy, completeness, or usefulness of any information, apparatus, product, or process disclosed, or represents that its use would not infringe privately owned rights. Reference herein to any specific commercial product, process, or service by trade name, trademark, manufacturer, or otherwise, does not necessarily constitute or imply its endorsement, recommendation, or favoring by the United States Government or any agency

thereof. The views and opinions of document authors expressed herein do not necessarily state or reflect those of the United States Government or any agency thereof, Argonne National Laboratory, or the University of Chicago. 


\begin{abstract}
Shelter-in-place (SIP) is considered a credible alternative to immediate evacuation to protect the population on and around Army chemical warfare agent stockpile storage sites from accidental agent releases of short duration. To be effective, this strategy requires immediate SIP to minimize initial exposure to agent vapor, followed by timely and appropriate termination of SIP to minimize additional exposure to agent vapor accumulations in the shelter when the air outside becomes less hazardous. However, a major challenge facing emergency managers has been how to decide the best time and way to end SIP to obtain this ideal. This report describes a concept to make this decision, and suggests a methodology to apply the concept as a site-specific response tool.
\end{abstract}

The major conditions that influence the exposure of a population are the source term values of the agent that is released, meteorological conditions, shelter air change rates, the distance of the shelter from the source, and the dose-response relationship of the hazardous material. The circumstances that contribute to overall exposure associated with a SIP strategy involve exposure during the time before taking shelter, exposure while sheltered due to vapor infiltration, and additional exposure (if any) following the termination of SIP. Options to end SIP are to resume normal activities with no restrictions, to ventilate the shelter but remain indoors, to exit from the shelter and remain nearby, or to relocate to a designated facility.

The optimal time and way to end SIP involves examining the relationships among the conditions and circumstances listed above to find the combination of these variables that gives the smallest area where a sheltered population might receive a certain level of toxic effect. For example, find the combination of times, conditions, and circumstances that produce the smallest area where fatalities are possible. In this case, the best time and action to end SIP to minimize fatalities is that combination of variables which produces the smallest area where this level of effect is expected.

The methodology to apply the concept is to use a computer model to examine the relationships among these conditions and circumstances (many of which are pre-planned default inputs), and display the best time and action to end SIP quickly, in a user-friendly format. A computer model that was developed to prove the concept and demonstrate the methodology (called the TSIP Model) is described in the report, and the use of the TSIP Model is illustrated in a case study in an appendix to the report.

The report also discusses public education and emergency instructions essential for implementing this concept, and makes recommendations for agreements, plans, and exercises relevant to deciding when and how to end SIP.

This concept and methodology is independent of the atmospheric dispersion model used, and is not limited to chemical warfare agent vapor hazards. Thus it can help make decisions on when and how to end SIP following the accidental release of many other non-flammable nonreactive hazardous vapors if sufficient information is available about the characteristics of the material and the circumstances of the release. 


\section{CONTENTS}

Section 1: Introduction 1

$1.1 \quad$ Purpose

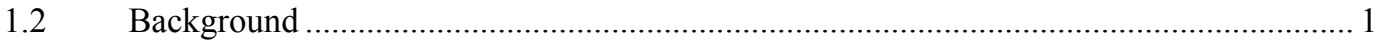

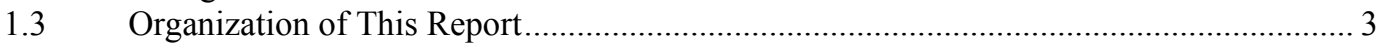

Section 2: Concept to Decide When and How to End Shelter-In-Place ........................................... 4

2.1 Consideration for Where and Why Persons Take Shelter ................................................. 4

2.2 Important Influences on When to End Shelter-In-Place.................................................. 4

2.3 Circumstances That Contribute to Exposures in Sheltered Populations............................... 6

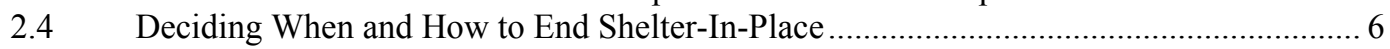

Section 3: Methodology to Decide When to End Shelter-In-Place

3.1 Use of Dispersion Modeling to Decide the Ending of Shelter-In-Place .............................. 8

3.2 Use of Monitoring to Decide the Ending of Shelter-In-Place .......................................... ..9

3.2.1 Monitoring Considerations .......................................................................... 9

3.2.2 Aerosol Deposition Considerations.................................................................... 10

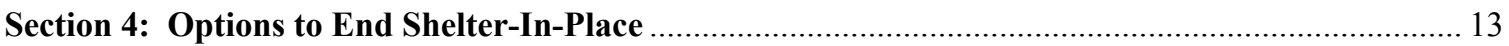

4.1 Resume Normal Activity With No Restrictions .......................................................... 13

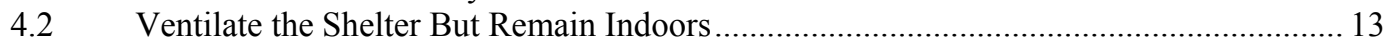

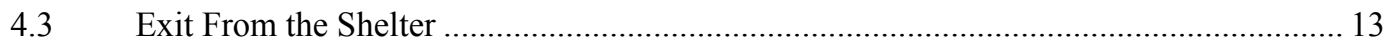

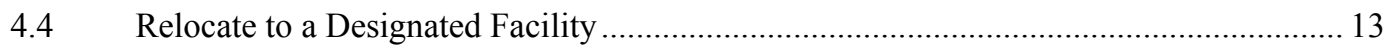

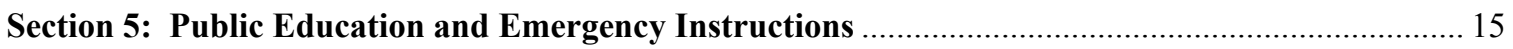

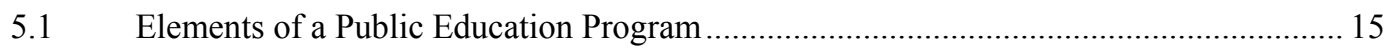

E.2 Emergency Instructions to a Population in Shelters ..................................................... 16

Section 6: Recommendations for Agreements, Plans, and Exercises .............................................. 18

6.1 Memorandums of Agreements and Protocols ............................................................... 18

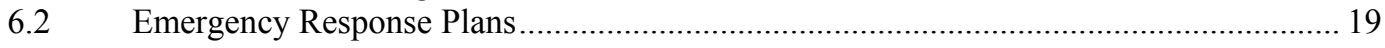

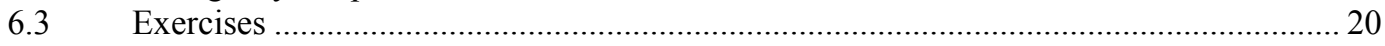

Appendix A: Case Study to Decide When to End Shelter-In-Place................................................. A-1

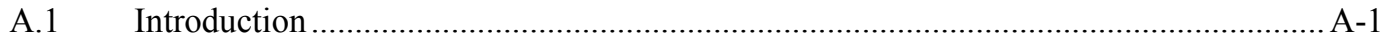

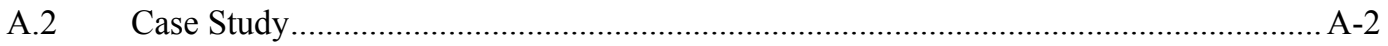

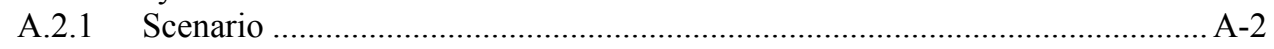

A.2.2 Hazard Analyses Using D2PCw ………........................................................ A-3

A.2.3 Describing the Scenario in TSIP ................................................................ A-8

A.2.4 Exploring Sheltering Options Where Fatalities Might Occur ........................ A-15

A.2.5 Exploring Sheltering Options Where Fatalities Are Not Expected ................. A-21

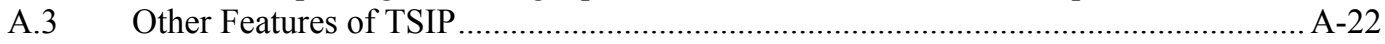

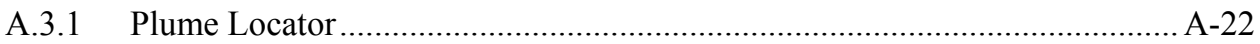

A.3.2 Concentration Indicator Bars ............................................................ A -23

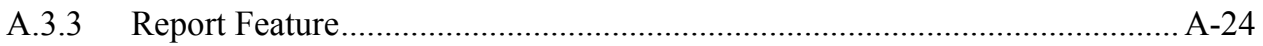




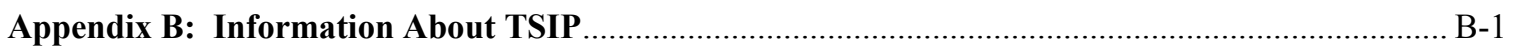

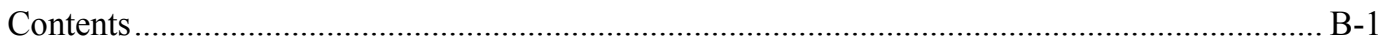

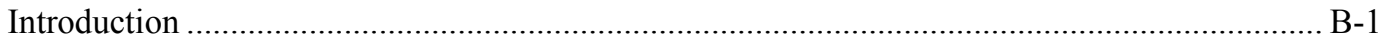

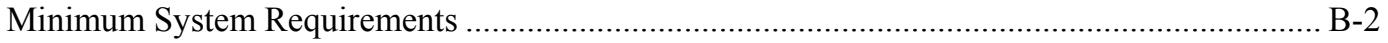

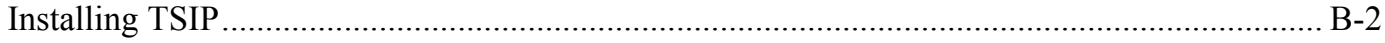

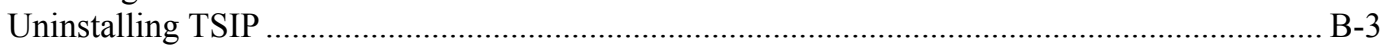

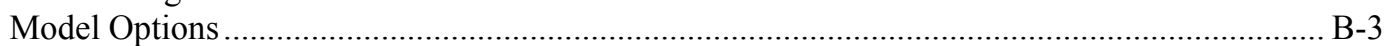

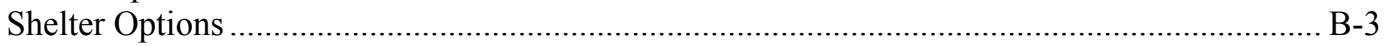

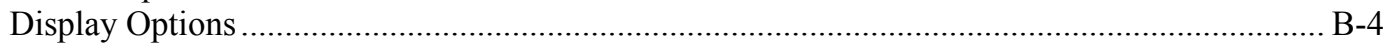

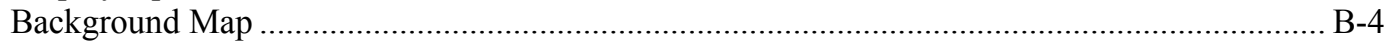

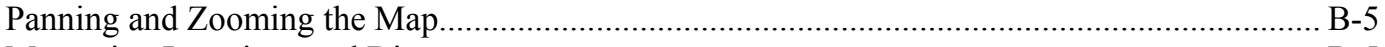

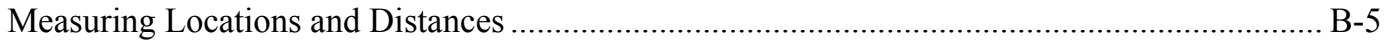

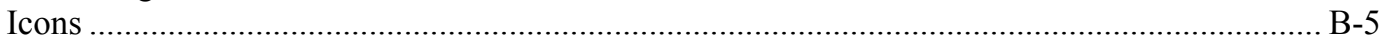

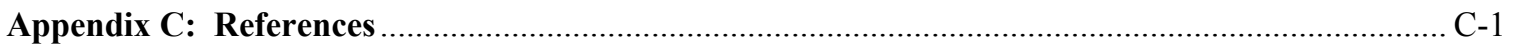

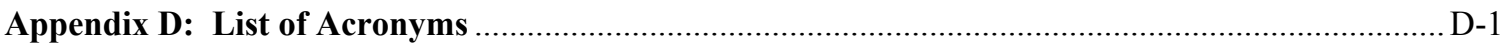




\title{
When and How to End Shelter-In-Place Protection From a Release of Airborne Hazardous Material: Report on a Decision-Making Concept and Methodology
}

\author{
by
}

\author{
George D. Yantosik, Ken Lerner, Dan Maloney, and Fred Wasmer
}

\section{SECTION 1}

INTRODUCTION

\subsection{PURPOSE}

Temporary shelter-in-place (SIP) is the combination of prompt sheltering of a population in enclosed structures to minimize initial exposure to airborne hazardous material, followed by timely and appropriate termination of SIP to minimize exposure to hazardous vapor accumulations in the shelter. ${ }^{1}$ Temporary SIP has long been recognized as a complement or alternative to immediate evacuation to protect the population on and around Army chemical stockpile storage sites. However, a major challenge facing Chemical Stockpile Emergency Preparedness Program (CSEPP) emergency managers and protective action decision-makers who are striving for this balanced approach is the limited guidance about when and how to end SIP to minimize the overall exposure of the population.

This report responds to this challenge by describing a concept to decide when and how to end SIP, and suggesting a methodology for this decision-making that can be developed into a site-specific response tool.

\subsection{BACKGROUND}

Shelter-in-place is a protective action that has been used successfully for years for protection against a variety of airborne hazards. Shelter-in-place is supported by laboratory and field experiments, and endorsed by experts in emergency response. CSEPP guidance and Army literature also identify SIP as an appropriate protective action under some circumstances, provided that SIP is terminated in consideration of the infiltration of hazardous vapors into shelters during the passage of the plume (Yantosik et al. 2001). The Planning Guidance for the CSEPP advises that:

\footnotetext{
${ }^{1}$ The acronym SIP used in this report is pronounced "sip."
} 
"Shelter feasibility is determined by the infiltration rate into the structure and the duration that the structure is in the plume. In general, sheltering is not a good protective action when the accident is of a long duration or if the structure has a high infiltration rate. Moreover, people must vacate or air out the shelter when the plume has passed in order to minimize exposure to chemical vapors that entered the shelter while it was in the plume." (CSEPP 1996, p. D-4)

Thus timely termination of SIP as protection from infiltrating vapors must be an integral component of a SIP strategy.

Neither the Planning Guidance for the CSEPP (CSEPP 1996) nor DA Pamphlet 50-6 (U.S. Army 1991) advises how to link release scenarios or plume duration estimates to protective action decisions, nor do they directly address the issue of deciding when to ventilate or exit shelters, other than to end SIP after the plume has passed. Chemical Accident Incident Response and Assistance (CAIRA) plans at and around Army chemical storage sites do not address concepts and methods for ending SIP (Yantosik et al. 2001, paragraph 2.6). Responses observed during recent CSEPP exercises, when demonstration of SIP was attempted, indicated that decision-makers would rely primarily on an atmospheric dispersion model to estimate when hazardous vapors dissipated within areas where they might have had some toxic effect on an unprotected population. Attempts to monitor the atmosphere at ground level for the absence of agent vapors in these areas might also be made. The decision to end SIP would then be based on a combination of model projections that the vapors are gone, and inferences from some monitoring results that this is true. There was no indication of attempts to refine the decision on the time and way to end SIP to take advantage of the benefit of temporary SIP, especially to reduce the exposure of the population closest to the release that is at risk of potentially fatal toxic effects.

This problem prompted the Federal Emergency Management Agency to ask Argonne National Laboratory (ANL) to identify a concept and methodology for deciding when and how to terminate SIP. This methodology, in turn, could be the basis for sitespecific operational guidelines for ending SIP at each of the eight Army chemical stockpile storage sites, and in the off-post communities surrounding them.

This ANL project consisted of two tasks. Task 1 was to collect and analyze existing literature that might be relevant to making decisions about the termination of SIP. Temporary Shelter-In-Place as Protection Against a Release of Airborne Hazardous Material: Report of a Literature Search (Yantosik et al. 2001) documented the results of Task 1. One of the conclusions in the report was that "no off-the-shelf decision making methods are available for determining when and how sheltered populations should act to minimize exposure to accumulations of hazardous vapors within the shelter." (p. 43) The literature search served as the baseline for Task 2, which required ANL to invent a concept to decide when and how to end SIP, and develop a corresponding methodology for making this decision. The results of Task 2 are described in this report. 


\subsection{ORGANIZATION OF THIS REPORT}

The body of this report is divided into six main sections.

- Concept to Decide When and How to End Shelter-In-Place. (Section 2) This section discusses where and why persons might shelter-in-place, the important conditions that influence when to end SIP, and the circumstances that contribute to exposures associated with SIP. This section then outlines a concept for deciding when and how to end SIP based on a combination of modeling and accident-site monitoring.

- Methodology to Decide When to End Shelter-In-Place. (Section 3) This section describes a proposed methodology to decide the timing of the termination of SIP, using the Terminate Shelter-In-Place (TSIP) computer model developed by ANL to prove the concept and illustrate the methodology. ${ }^{2}$ This section also discusses problems with monitoring as an adjunct to making this decision.

- Options to End Shelter-In-Place. (Section 4) This section discusses the options upon ending SIP, and suggests how to decide among options.

- Public Education and Emergency Instructions. (Section 5) This section addresses the public education effort essential to the success of temporary SIP.

- Recommendations for Agreements, Plans, and Exercises. (Section 6). This section discusses requirements for memorandums of agreement, protocols, and plans to ensure the success of temporary SIP. This section also proposes that the scenario design and extent-of-play agreements in CSEPP exercises be expanded to include making and implementing decisions about ending SIP.

Appendix A is a case study using the TSIP model to demonstrate the proof-ofconcept, and illustrate the proposed methodology for deciding when and how to end SIP. ${ }^{3}$ This appendix can also serve as a primer to using the TSIP model. Appendix B contains the TSIP Model Readme file and User's Manual, which describes the features of the model. Appendix C lists references cited in this report. Appendix D defines acronyms used in this report.

\footnotetext{
${ }^{2}$ The acronym TSIP used in this report is pronounced "T-sip."

${ }^{3}$ The TSIP model is for proof-of-concept only. It has not been subjected to all of the procedural reviews and independent verification required for use as a decision-making tool in CSEPP.
} 


\section{SECTION 2}

\section{CONCEPT TO DECIDE WHEN AND HOW TO END SHELTER-IN-PLACE}

This section discusses where and why persons might shelter-in-place, the important conditions that influence when to end SIP, and the circumstances that contribute to exposures associated with SIP. This section then outlines a concept for deciding when and how to end SIP using a combination of modeling and accident-site monitoring. The proof of this concept is discussed in the next section of this report. Sections 3 and 4 of this report discuss a methodology to implement this concept.

\subsection{CONSIDERATION FOR WHERE AND WHY PERSONS TAKE SHELTER}

In order to decide when and how to end SIP, hazard analysts and decision-makers must consider all of the places where persons might take shelter, and why. According to information in the literature about SIP, in CSEPP guidance documents, in Army and local off-post jurisdiction plans, and in reports of CSEPP exercises, the main reasons people are asked to take shelter are because:

- They are within an area where exposure to the hazardous vapor is possible, and there is not sufficient time for them to evacuate, or they cannot evacuate because of a disability or lack of transportation.

- They are within a sub-zone ${ }^{4}$ touched by the hazard wedge calculated by D2PC or the risk envelope calculated by D2-Puff, even though they are outside of the wedge or envelope. This population is not considered likely to be at risk. Their SIP is more of an artifact of the placement of zone boundaries, but creates a potentially very large sheltered-in-place population.

See Section 5 in Temporary Shelter-In-Place as Protection Against a Release of Airborne Hazardous Material: Report of a Literature Search (Yantosik et al. 2001) for a summary of other reasons why a population might take shelter.

\subsection{IMPORTANT INFLUENCES ON WHEN TO END SHELTER-IN-PLACE}

The most important variables involved in deciding when to end SIP are: 1) source term values; 2) meteorology; 3) shelter air change rates; 4) distance of shelters from the source; and 5) the dose-response relationship employed.

- Source Term Values. The initial protective action decisions to evacuate or SIP may justifiably be based on an appropriate Maximum Credible Event (MCE) in the absence of detailed information about the accident. However, safe-sided

\footnotetext{
${ }^{4}$ Sub-zone, as used in this report, refers to locally established sub-zones within the CSEPP Emergency Planning Zone.
} 
assumptions about the event (i.e., those that are generally thought to be conservative), can skew the timing of the termination of SIP, and significantly erode the protection offered by sheltering. Therefore, if initial responses are based on assumptions from the work plan MCE for a chemical operation, it is imperative that the actual mode, quantity, and duration of the release be ascertained as soon as possible. Source-term observational data (from eyewitnesses at the accident site) and source term monitoring data (from monitors at and downwind from the accident site) should be the primary inputs to define the source-term values for dispersion modeling to decide when to end SIP.

- Meteorology. Wind speed, wind direction, and atmospheric stability class are the key variables that are used within dispersion models to predict the dispersion of hazardous vapors. The more accurately the meteorological conditions are described in the model, the more accurately the dispersion can be modeled to show representative plume concentration histories at various locations.

Fortunately, Army installations storing chemical warfare agents (CWA) already are equipped with meteorological towers so that useful meteorological data can be obtained in near-real time. Where wind speed and direction vary significantly over relatively short distances (e.g., around complex terrain features), the dispersion model should allow for the inclusion of enough meteorological information (e.g., from multiple elevations and/or locations) to accurately describe the conditions that will affect model output.

- Shelter Air Change Rates. The duration that a given shelter will provide useful protection for a given release scenario will depend in part on the shelter's air infiltration rate. According to Oak Ridge National Laboratory Report ORNL-6615 (Rogers et al. 1990), typical or normal shelters have an air infiltration rate on the order of 1.5 air changes per hour $(\mathrm{ACH})$. A very leaky shelter might have a very high infiltration rate (up to $5.0 \mathrm{ACH}$ ), while enhanced and expedient shelters have very low infiltration rates.

- Distance of Shelters From the Source. Shelters closer to the source of the release will usually be exposed sooner, and to higher concentrations, than shelters further downwind. Therefore, the optimum time to end shelter protection will usually be sooner for closer shelters than for shelters that are further out. This variable, in the form of plume concentration history as a function of time, can be addressed in some way in all of the approved CSEPP dispersion models.

- Dose-Response Relationship. The toxic effects model and methodology used to determine the toxic effect from a CWA release is of special importance in determining when to end SIP. Currently the linear, cumulative dosage model (i.e., using the No Effects ${ }^{5}$, No Deaths ${ }^{6}$, and $1 \%$ Lethality values) is used in the CSEPP. The Acute Exposure Guideline Level (AEGL) toxic effect model (e.g.,

\footnotetext{
${ }^{5}$ The No Effects dosage is a calculated dosage from a chemical agent release below which a toxicity level is not expected to have short-term adverse effects on healthy adults.

${ }^{6}$ The No Deaths dosage is the largest dosage that would result in no fatalities to healthy adults.
} 
AEGL-2, AEGL-3), which is not linear for the nerve agents (i.e., the toxic effect is a non-linear function of the concentration history profile) is a method that might be used in the CSEPP following the EPA comment and approval process. ${ }^{7}$ The methodology to decide when to end SIP that is described in this report works with either of these toxic effect models.

\subsection{CIRCUMSTANCES THAT CONTRIBUTE TO EXPOSURES IN SHELTERED POPULATIONS}

The timing of sheltering actions taken by the affected population will also influence the optimum time to end SIP, i.e., consideration must be given to toxic effects that occur before, during, and after the population is sheltered.

- The potential exists for some toxic load to accumulate before persons enter their shelter if they are still outside after the hazardous vapors reached their location.

- Some additional toxic load can accumulate while persons are in the shelter due to infiltration of hazardous vapors into the shelter.

- Finally, the potential for additional toxic load accumulation following SIP occurs when persons remain in the building while the shelter ventilates, when persons exit from shelter but remain just outside the building during the ventilation period, and while persons relocate to an area away from the effects of the plume.

Poor timing of sheltering actions can result in greater toxic effects than remaining outdoors with no protection.

\subsection{DECIDING WHEN AND HOW TO END SHELTER-IN-PLACE}

Current atmospheric dispersion models used in CSEPP will calculate and display the area where a population will be exposed to some toxic effect if they have no protection while the vapor plume is in the area. This is represented by a wedge shaped area on a map using D2PCw, or by a comparable risk envelope displayed on a map using D2-Puff. D2-Puff can also display the area where a population that was sheltered indefinitely from the time of the release will be exposed to some toxic effect, and vary the shelter air change rate used for this calculation. However, neither model calculates the total exposure to a population before, during, and following a temporary sheltering action to determine when and how to end SIP.

The ANL-proposed concept described in this report is based on the premise that a sheltered population is afforded more protection than remaining outdoors, at least temporarily. The value of this sheltering action can be understood as a reduction in the area where a particular level of toxic effect is possible, compared with the larger area

\footnotetext{
${ }^{7}$ Information about AEGLs for nerve and mustard agent can be found in the Federal Register,Vol.66, No.85, pp. 21940-21964 (May 2, 2001)
} 
where this same level of toxic effect is expected for unprotected persons outdoors. The proposed concept is simply to examine the relationships among the variables that determine how much exposure a population that takes temporary shelter will receive, and find the combination that produces the smallest area of the given toxic effect. The best time and way to end SIP is that which is associated with the smallest area. Thus, for example, it is possible to decide when and how to end SIP to produce the smallest area where fatalities are possible, since the level of toxic effect is one of the variables considered in this concept. This enables decision-makers to apply the CSEPP policy that "the most important objective of the emergency preparedness and implementation process is the avoidance of fatalities to the maximum extent practicable, should an accidental release of chemical agent occur." (CSEPP 1991)

This concept even allows decision makers to identify and avoid circumstances where SIP might produce greater toxic effects among a sheltered population than would have occurred had they simply remained outdoors and taken no protective action. This phenomenon could result if persons in an area do not take shelter until the plume passes, thus suffering the effects of the maximum outdoor exposure, and then suffer additional exposure in a shelter infiltrated by hazardous vapors. A similar condition could occur if the best time for persons close to the release to end SIP is delayed until the plume passes locations further downwind, where life-threatening effects are not expected regardless of the PAD. This trade-off could increase the possibility of fatalities in locations closer to the accident site.

This concept, and the methodology described in Sections 3 and 4, is independent of the atmospheric dispersion model used, and is not limited to CWA vapor hazards. The concept and methodology can be used with atmospheric dispersion models other than D2PCw and D2-Puff. It can help make decisions on when and how to end SIP following the accidental release of many other non-flammable non-reactive hazardous vapors if sufficient information is available about the characteristics of the material and the circumstances of the release. 


\section{SECTION 3}

\section{METHODOLOGY TO DECIDE WHEN TO END SHELTER-IN-PLACE}

This section introduces a proposed methodology to decide the timing of the termination of SIP. This section also discusses monitoring as an adjunct to deciding about ending SIP.

\subsection{USE OF DISPERSION MODELING TO DECIDE THE ENDING OF SHELTER-IN-PLACE}

The methodology proposed by ANL to apply the concept described in the preceding section is to use a computer program with dispersion modeling to examine the relationships among variables that influence the value of temporary SIP, in order to identify the best time and way to end SIP. The TSIP model computer program proof-ofconcept developed by ANL is used in this section and in Appendix A to illustrate this methodology.

To apply the methodology, a hazard analyst or decision-maker would first use an approved atmospheric dispersion model with a new routine or module (such as the one in the TSIP model) to calculate when SIP should be ended in a given sub-zone in order to minimize fatalities. This is done by selecting possible fatalities as the threshold value for toxic effects, entering information about the conditions and circumstances that influence the size of the area where exposures are possible, and selecting a first approximation of shelter termination times and options. When the best available information about each variable is entered, the model will calculate the area where persons are subject to lethal toxic effects for the specified time in shelter and SIP termination option. The hazard analyst or decision-maker then varies the time in shelter and termination options. As changes are made, the area under consideration may increase or decrease. If an area is reduced in size when variables are adjusted, this trend should be followed until the minimum area is obtained, thus finding the smallest area where lethal toxic effects might occur. It is possible that part of a sub-zone can be above a toxic effect threshold because of toxic load from high vapor concentrations in shelters, while another part of the subzone is above the same toxic effect threshold because of toxic load from high vapor concentrations outdoors. The TSIP model will display both areas as exceeding the threshold, but they might not be contiguous. In most cases the time to end SIP should be increased to eliminate this bifurcation. ${ }^{8}$ Ultimately, the shelter termination time and option associated with the smallest area is the best time and way to end SIP to minimize fatalities in that sub-zone.

\footnotetext{
${ }^{8}$ Some existing sub-zones are so large that they might be unwieldy to manage as the bounds of areas to terminate SIP. If local officials determine that an existing sub-zone is too large to manage SIP termination when planning for this option, consideration should be given to dividing the sub-zone into two or more areas, or relying on local landmarks bounding the area instead of sub-zone identification numbers.
} 
The hazard analyst or decision-maker would then select non-lethal effects as the threshold value of concern, and make a similar set of calculations to find the smallest area where non-lethal effects might occur. These calculations will show the optimum shelter termination time and option to minimize exposure to non-lethal effects in that sub-zone. Thus decisions on when to end SIP would not be limited to areas of potentially lethal effects.

If the hazard area of concern affects more than one sub-zone, the optimum time and option to end SIP should be calculated separately for each sub-zone using appropriate toxic effect thresholds. The hazard analyst can also explore the implications of different shelter air change rates to determine if variation in shelter types might impact the optimum time to end SIP.

The TSIP model displays the products of all of the above calculations graphically and in tabular format, according to the preferences of the user, to help analysts and decision-makers to quickly decide on the best course of action for their threshold of concern. The process of finding the optimal SIP termination time and option manually that is used in this proof-of-concept routine can be automated by adding an additional routine for this task, if that is preferred to the manual method.

The dispersion model built into the TSIP model uses slightly different algorithms than are used in the current CSEPP approved dispersion models, so the TSIP model cannot be used as a decision-making tool as is. However, this does not impact on the use of the TSIP model to prove the concept. Based on work done to date, the authors of this report believe that this methodology and the routine embedded in the TSIP model is compatible with CSEPP approved dispersion models, and with current CSEPP emergency management information systems and alert and notification protocols. If developed fully as a decision tool, the methodology in the TSIP model could be embedded in any dispersion model such as D2PCw or D2-Puff. However, if used with D2PCw or D2-Puff, the conservative values in these models that impact the time to end SIP should be examined and perhaps adjusted. It also is important that the model used to decide when to end SIP account for local site features that can affect transport time (e.g., terrain and vegetation effects), so that these factors are properly considered. The D2-Puff model currently does consider terrain features. (Prater et al. 1998)

See Appendix A for a case study on deciding when to end SIP using the TSIP model. See Appendix B for more information about the TSIP model.

\subsection{USE OF MONITORING TO DECIDE THE ENDING OF SHELTER-IN- PLACE}

\subsubsection{Monitoring Considerations}

As indicated in Section 2, monitoring by the Army in and around the accident site to obtain the best available information about the source term is critical to decisions about ending SIP. This monitoring should have the highest priority if monitoring assets are 
limited, because it is the baseline upon which the most important PARs and PADs depend.

Modeling is not expected to produce a perfect solution because some of the inputs are not perfect descriptions of reality. Also, some of the algorithms in approved hazard analysis models have a conservative bias, i.e., they safe-side some values in a way that could skew the time calculated to end SIP. Therefore, there may be a desire by decisionmakers to consider some monitoring results from off-post locations before ending SIP based on model projections. Data from the vicinity of concentrations of shelters would be especially desirable. However, just as modeling has limits, so does monitoring.

First, the optimum time to end SIP where it will do the most good (i.e., in areas where potentially lethal effects are possible) might be so soon after the initial release occurred that there will be no time to do any monitoring other than at and around the accident site, though there might be time to collect downwind data at the facility perimeter in some circumstances. The display from the TSIP model that identifies when SIP should be ended can be used to estimate how much time is available, if any, to collect and assess off-post monitoring results before the protection of SIP wanes. Populations that are sheltered from the highest potential plume concentrations are the populations for whom SIP provides protection for the shortest period of time. The optimum time for them to end SIP might be very soon (e.g., less than an hour) after a high concentration release of short duration. Any delay in ending their SIP, such as to obtain results of monitoring in their vicinity, could be life threatening. However, since they are the closest to the source, they should enjoy the highest confidence in decisions based on modeling if the model input includes the most current eyewitness information and the results of realtime monitoring at and downwind from the accident site.

Second, it is a difficult art to interpret the meaning of ground level point-source detection results off-post to characterize the history or predict the future of a moving plume of vapor in a large volume of air, and the results are never conclusive. The absence of detectable vapors at any one location at any one time does not necessarily mean that there are not health threatening concentrations elsewhere in the area. Similarly, the detection of very low concentrations of vapors at any one location does not necessarily mean that there is a significant hazard outdoors anywhere in the area. Intentional delay in terminating SIP to obtain inconclusive monitoring results is not attractive if the outcome is increased exposures and more fatalities.

For these reasons the methodology described in this report does not rely on realtime monitoring results from locations off-post.

\subsubsection{Aerosol Deposition Considerations}

The atmospheric dispersion models used in CSEPP do not estimate the potential for agent aerosol deposition on vegetation, ground surfaces, buildings, or equipment from the release of a persistent CWA. If there is a potential for airborne dispersion of a persistent CWA as an aerosol, this will be indicated 
primarily by the visible signature of the mode of release of the agent. Therefore, in the absence of dependable quantitative information about the potential for aerosol deposition associated with a chemical accident during the response phase, there is little choice but to use qualitative estimates. Initial judgments should be based on the best information available about the release, the atmospheric conditions at the accident site and down wind, and the expert knowledge of Army hazard analysts. Reports from surface monitoring by Army teams at and downwind from the accident site can help if monitoring results can be obtained quickly. These informed judgements should be adjusted immediately as new information becomes available. This is not unreasonable, considering that the generation of aerosol deposition beyond the installation boundary is such a remote possibility, and the conditions that would generate aerosol deposition are easily identified. ${ }^{9}$ The absence of these indicators justifies ignoring aerosol deposition when making SIP decisions off-post.

\subsubsection{Release of a Non-Persistent Chemical Warfare Agent}

A release of the non-persistent CWA GB should be considered by hazard analysts as producing only a vapor hazard off-post, regardless of the mode of release of the agent. It is unlikely that areas close to the source where SIP is implemented can be monitored in time to determine when concentrations outside of shelters are less than within shelters. Spot sampling with a real-time monitor only provides information about a specific location at a specific time, and is of questionable value to a decision on terminating SIP. Approved models using the best available source term values and near real-time meteorological data should be used by the Army to make PARs to terminate SIP. Officials in off-post jurisdictions will make the final decision about ending SIP in their jurisdiction, based on Army PARs and their knowledge of other conditions and circumstances in their jurisdiction at the time.

\subsubsection{Release of a Persistent Chemical Warfare Agent}

A release of persistent CWAs VX and mustard also should be considered by hazard analysts as producing only a vapor hazard off-post, unless there is reason to believe that an agent aerosol of consequence was transported beyond the installation boundary. If vapor is the only hazard of concern, the same guidance applies as for a non-persistent agent above. If there is reason to believe that an aerosol deposition hazard extends off-post, the Army will consider this in addition to the results of modeling when making PARs on when and how to end SIP. However, it is not expected that the presence of low levels of aerosol deposition, or vapors from the re-volatilization of aerosol deposition, will inhibit any action

\footnotetext{
${ }^{9}$ An unusual combination of factors is needed to make aerosol deposition a possible health risk beyond the installation boundary. A number of explosively configured munitions filled with persistent agent (VX or mustard) are needed to create many large aerosol droplets upon detonation. It also requires a fire hot enough to cause the munitions to detonate and carry the aerosols well above ground level in a heated plume (e.g., plume rise). In addition, the right atmospheric conditions are needed to transport the aerosol significant distances, in order for the droplets to fall out beyond the installation boundary.
} 
required to terminate SIP to protect a population from the vapor hazard posed by the release. 


\section{SECTION 4}

\section{OPTIONS TO END SHELTER-IN-PLACE}

This section discusses the options upon ending SIP, and suggests how to decide among options. Recommendations on how to end SIP will depend on several variables. Ventilation of the shelter is important if the shelter is within the hazard wedge or risk envelope, and the occupants are going to remain inside because they cannot exit. If they are going to exit or relocate, ventilation is not that important, and might result in additional harmful exposure in the process. Also, some people might be reluctant to leave their homes unsecured, and delay their exit and relocation while they secure their valuables, or collect their valuables to take with them.

\subsection{RESUME NORMAL ACTIVITY WITH NO RESTRICTIONS}

Resuming normal activity with no restrictions would be an appropriate action for persons who were never in danger, but who were sheltered as a precaution. This is the usual interpretation of "All Clear."

\subsection{VENTILATE THE SHELTER BUT REMAIN INDOORS}

In some cases the best action to end SIP might be to remain indoors but ventilate the building by opening doors and windows, removing tape and plastic installed during expedient sheltering, and turning on ventilation equipment. This might be the only option for disabled persons or special populations who lack the mobility to exit the shelter. This option also might apply when the weather is so dangerous that remaining outside for an extended period is inadvisable, or there is believed to be some other hazard outdoors to be avoided.

\subsection{EXIT FROM THE SHELTER}

In order to decrease the overall exposure, it might be appropriate to instruct the public not to take the time to open windows, remove tape, turn on ventilation equipment, etc, prior to leaving the building. Rather, they should simply go outside and let the building ventilate itself gradually. The potential for aerosol deposition should be a minor consideration since it is such a remote possibility, and not likely to be a safety factor at great distances from the source even if an agent aerosol is generated by the event. See paragraph 3.2.2 in the previous section. This might also be the best option for persons who lack transportation to relocate.

\subsection{RELOCATE TO A DESIGNATED FACILITY}

Local officials may direct that upon the termination of SIP, sheltered populations should relocate to designated facilities to be accounted for and medically screened for agent exposure symptoms. (CSEPP 1996, Appendix E) In this case the instructions 
would be to exit from shelters and proceed immediately to a place where this follow-up can occur. Instructions should identify the routes to take to avoid re-encountering the plume, and to avoid traffic bottlenecks. Designated routes and facilities for relocation might not be the same as for an initial evacuation. In dire circumstances, such as if the duration of the release is longer than originally expected and SIP is no longer a good choice, sheltered persons might be asked to relocate immediately to a safer place. 


\section{SECTION 5}

\section{PUBLIC EDUCATION AND EMERGENCY INSTRUCTIONS}

The importance of public education with regard to SIP is mentioned often in the literature that ANL reviewed (Yantosik et al. 2001 P. 14). Public education must explain the vapor infiltration concern; yet convince the potentially affected population that SIP is a viable action if this protection is ended at the appropriate time. The education program should include specific information about how the public will be told when to end SIP, and that this instruction might come very soon after the initial direction to take shelter. It is also important that the actual SIP notification messages are consistent with the public education program that explains the SIP protective action messages, so the public will not be confused or misunderstand what they are being asked to do. The public also needs to be educated about what actions to take to end SIP. It is too simplistic to announce "All Clear."

This section focuses on the termination of SIP. It does not address other aspects of a total SIP public education program, such as the trade-off between initial evacuation and SIP. The information in this section is grouped in two topics: 1) elements of a public education program to address termination of SIP, and 2) emergency instructions to a population in shelters.

\subsection{ELEMENTS OF A PUBLIC EDUCATION PROGRAM}

A program of pre-emergency public education should convey the following to ensure timely and effective public response to end SIP during an actual emergency.

- The hazard of concern is primarily a vapor. The hazard will most likely be an invisible and odorless vapor that is transported downwind as a plume that expands and dilutes as it travels, and eventually dissipates.

- Vapor infiltration can reduce the protection of a shelter over time. A population can reduce the risk of exposure to hazardous vapor by going indoors and shutting off ventilation to the outside. However, every building leaks air, and outside vapors will infiltrate shelters that are in the path of the plume. Thus, as outside air infiltrates the shelter, the protection afforded by the shelter gradually declines. Eventually, sometime after the highest concentration of the vapor plume has passed the shelter, outside air will be cleaner than the air inside the shelter. Officials will consider this fact when instructing the sheltered population to ventilate or leave their shelters.

- Shelter-in-place is a temporary, two-step process. First a population must quickly take the best shelter available. Then the population must end this protective action when instructed. 
- Timing is important in both steps of this process. Taking shelter-in-place immediately when instructed will minimize exposure to toxic vapors, provided that one also ventilates or leaves the shelter immediately when instructed.

- Shelter-in-place must include an exit strategy. When taking shelter one should bring a radio tuned to the local Emergency Alert System (EAS) station, in order to receive instructions about when and how to end shelter-in-place. (This direction might be modified to accommodate Tone Alert Radios [TARs] in those jurisdictions where TARs are installed.)

- There are options for ending shelter-in-place. When local officials have decided that shelter-in-place should be ended in an area, the sheltered population may be instructed to resume normal activity without restrictions, to ventilate shelters but remain indoors, to exit from shelters but remain nearby, or to relocate to a designated facility for reasons such as accountability or medical screening.

\subsection{EMERGENCY INSTRUCTIONS TO A POPULATION IN SHELTERS}

Emergency instructions must be consistent with public education materials, and vice versa. Instructions during an emergency should describe actions and choices that have been previously introduced in public education materials, and use the exact terms and phrases used in these materials. Due to the short time available for messages on the EAS, sirens, and TARs, there is no opportunity for these messages to explain the practical meaning of terms such as "shelter-in-place" or "relocate." Their meaning must be explained and the groundwork laid for action ahead of time through an effective and comprehensive public education program.

Regardless of the scope and effectiveness of the public education program, actual emergency instructions must be as clear and concise as possible, because the affected population will probably include some who were not reached by the SIP public education program, such as transients and new arrivals. In addition, local officials and other credible community leaders should provide supplemental emergency information and explanation through media outlets to reinforce emergency instructions broadcast on alert and notification systems.

Instructions to the public while in shelters should be repeated at frequent intervals. They should be encouraged to sustain this protection and remain alert for directions on when and how to end their SIP. Instructions should also direct persons in the sub-zone to take SIP immediately if they have not yet done so, and reiterate basic SIP instructions. This includes how to use SIP kits if provided, or how to improvise other expedient measures to improve the protection of the shelter.

Instructions to the sheltered population should include the time that is optimal for ending SIP, the preferred way to end SIP for the sub-zone, and alternatives if the 
preferred option is not possible. It should be remembered that instructions to end SIP are appropriate even for areas where evacuation was recommended, in the event that some persons could not or would not evacuate. 


\section{SECTION 6}

\section{RECOMMENDATIONS FOR AGREEMENTS, PLANS, AND EXERCISES}

This section makes recommendations for memorandums of agreement, protocols, and emergency response plans related to terminating temporary SIP. What criteria will be used to decide when and how SIP will end? How will the information needed to make the decision be obtained? How much time is available to make this decision? What information is needed to prepare emergency instructions for broadcast? Who will authorize these broadcasts and how will the information be disseminated? How much time is needed to instruct the sheltered population after a decision to end SIP is made? What other information (e.g., about relocation routes and reception or mass care centers) will need to be provided to the public in conjunction with shelter termination messages? These are the kinds of questions that should be answered in agreements, protocols, and plans. In addition, this section discusses the need for CSEPP exercise scenario design and extent-of-play agreements to be expanded to include opportunities for SIP termination decision-making and the dissemination of related public instructions and emergency information.

\subsection{MEMORANDUMS OF AGREEMENT AND PROTOCOLS}

Army and off-post authorities should formally agree on what information concerning SIP will be exchanged among organizations during an emergency to ensure that this action will be timed and implemented effectively. Agreements should cover protocols and practical details about how the information will be communicated, comparable to arrangements currently in place for making initial PARs and PADs. This exchange could be addressed in separate agreements, or incorporated into existing agreements such as those pertaining to alert and notification or mutual aid. The following should be considered.

- The Army should provide projections of optimum shelter termination times for each sub-zone affected by the release as soon as possible after making the initial PAR, regardless of whether the initial PAR was to evacuate or SIP. These estimates should be used by local officials to anticipate SIP termination PARs and PADs.

- All emergency response officials should immediately share PADs made within their jurisdiction with all other jurisdictions involved in the response to the accident. This includes sharing of Army PADs with off-post officials, and vice versa. This will enable all jurisdictions to anticipate the impact that a PAD in one sub-zone will have on other sub-zones regarding mutual assistance with relocating and medically screening persons who were sheltered-in-place. Off-post officials should also inform the Army when the direction to SIP was broadcast in each subzone, and how long the officials believe it took or will take the population to execute this PAD. This will enable the Army to provide better PAR updates. 
- The Army should provide PARs to end SIP for each sub-zone affected by the appropriate, agreed-upon toxic hazard levels of concern (e.g., No Effects and no Deaths, or AEGL-2 and AEGL-3) as soon as possible, so off-post officials have time to consider the PARs and implement corresponding PADs. These updated PARs to end SIP should be provided regardless of whether the initial PARs were to evacuate or SIP, because some individuals might have taken shelter instead of evacuating. These PARs should be based on current information about conditions at the accident site, and information from off-post officials about the implementation of PADs to evacuate or SIP in each sub-zone.

\subsection{EMERGENCY RESPONSE PLANS}

The Army and each off-post jurisdiction should expand their CSEPP and CAIRA plans to cover the essential elements of a successful temporary SIP effort. The following should be incorporated in these plans.

- All plans should discuss the concept and methodology to end SIP in a timely and appropriate manner.

- All plans should discuss education of the public to understand and respond to instructions to end SIP. See Section 5 of this report for more information.

- All plans should include protocols for sharing SIP termination information with other jurisdictions as described in formal agreements. This includes feeding information to the Joint Information System and to the Joint Information Center.

- All plans should include procedures for the timely broadcast of instructions to end SIP, consistent with the public education effort and pre-planned emergency instructions. This should include consideration for broadcasting the direction to end SIP selectively within certain large sub-zones or in special facilities, especially if that will minimize the potential for fatalities. Consideration also should be given to broadcasting instructions to end SIP in sub-zones where the original PAD was to evacuate, to accommodate those persons who could not or would not evacuate.

- All plans should provide for support of the sheltered population upon termination of SIP. This includes the selection of relocation routes to avoid areas that might remain potentially hazardous, and the establishment of relocation and medical screening facilities that might be different from those set up to support an initial evacuation effort.

- In addition, the Army plan should describe how to expedite the collection of eyewitness information, and the results of monitoring at or near an accident site, to obtain real-time data about source term values in time for this information to be used for deciding about terminating SIP. The Army plan also should address how 
to collect eyewitness information and monitoring results to determine the potential for aerosol deposition, if the circumstances of the release suggest that this is a possibility. These Army plans should be explained to off-post officials to ensure their understanding of how the Army will decide PARs to end SIP.

- The Army plan also should cover the need to calculate SIP termination PADs for the on-post population (employees, contractors, visitors, and residents) immediately upon deciding the initial on-post PADs, regardless of the initial PADs implemented on-post. Similarly, the Army plan should provide for the calculation of SIP termination PARs immediately after issuing initial PARs (SIP or evacuate) to off-post officials. These calculations should be based on updated reports from the accident site to quantify the source terms more accurately than using an MCE.

\subsection{EXERCISES}

It would be beneficial to practice SIP termination decision-making and the dissemination of public instructions and emergency information during CSEPP exercises (CSEPP 1999). The scenario design and extent-of-play agreements in CSEPP exercises should be expanded accordingly. Key SIP elements to exercise include the following.

- Collecting and assessing eyewitness information from the accident site to support SIP termination recommendations and decisions.

- Collecting and assessing monitoring results from the vicinity of the accident site to support SIP termination recommendations and decisions.

- Deciding when and how to end SIP.

- Translating SIP termination decisions in to clear and timely public instructions and emergency information.

- Broadcasting public instructions via alert and notification systems (e.g., sirens, TARs, and EAS).

- Providing supplemental emergency information and explanation through media other than sirens, TARs, and EAS.

- Simulating feedback from the public and the media, through the public inquiries system and the mock media. Feedback should reflect probable public concerns and questions based on the local public education program and information generated by players during the exercise response. 


\section{APPENDIX A}

\section{CASE STUDY TO DECIDE WHEN TO END SHELTER-IN-PLACE}

This appendix presents a chemical accident scenario as a case study for the Terminate Shelter-In Place (TSIP) model to prove the concept invented by Argonne National Laboratory for this project. The case study also demonstrates the proposed methodology to apply the concept.

\section{A.1 INTRODUCTION}

The TSIP model, referred to simply as TSIP in this appendix, is a utility for exploring temporary shelter-in-place (SIP) strategies for protecting populations from chemical warfare agent (CWA) vapors.

Temporary SIP, if properly executed, is an effective way to protect populations from hazardous chemical vapors, especially from high concentrations for short periods. There are many parameters that influence the effectiveness of SIP. The most important are:

- The time-history of the vapor concentration outside the shelter.

- The toxicity of the hazardous vapor.

- $\quad$ The time after the initial release when SIP begins and ends.

- $\quad$ The rate at which the vapor infiltrates the shelter.

- Whether an attempt is made to ventilate the shelter after the plume passes.

- Whether the population relocates after exiting the shelter.

Using TSIP, a user can vary these parameters and explore the effectiveness of various sheltering options on a display map that highlights the area where the population is expected to receive a given toxic effect.

The concept and methodology that this model provides can be used to determine the smallest area where a population will suffer the toxic effect of concern (e.g., possible fatalities) for a given source term and meteorological conditions, based on the shelteringrelated actions of the population. The sheltering-related actions of the population include the time to take shelter, the time in the shelter, the protection their shelter affords, and the actions taken when SIP is ended. The optimum time and way to end SIP is that which produces the smallest hazard area for the conditions and circumstances. 
TSIP incorporates a basic Gaussian atmospheric dispersion model for predicting the dispersion of the chemical vapors. This model was used for simplicity to illustrate the concept and methodology. However, TSIP can be built into the Chemical Stockpile Emergency Preparedness Program (CSEPP) approved atmospheric dispersion models (i.e., D2PCw and D2-Puff). In its current form, TSIP only considers vapor releases of GB nerve agent, but could easily be extended to include other CWAs, as well as other hazardous chemical vapors.

Since the TSIP model was produced to prove the concept described in this report, and is a stand-alone model that is currently not integrated into D2PCw, all of the details of a given scenario must be described in TSIP. If TSIP were integrated into $\mathrm{D} 2 \mathrm{PCw} / \mathrm{PARDOS}$, then the meteorological parameters, the agent source strength as a function of time, and the plume concentration data, would already exist as either D2PCw/PARDOS input or output. The only additional information that would be required would be information related to the level of protection offered by the shelter (e.g., infiltration and ventilation rates) and information about the sheltering-related actions:

- $\quad$ Time Entered Shelter.

- $\quad$ Time Ventilated Shelter.

- Time Exited Shelter.

- $\quad$ Time Exited Hazard Area.

\section{A.2 CASE STUDY}

A case study using a hypothetical scenario is described in this section to illustrate the utility of the concept to decide when and how to end SIP, and to demonstrate the methodology of the TSIP model.

\section{A.2.1 Scenario}

During the movement of one pallet of fifteen GB-filled M55 rockets on the apron of a storage igloo, something happened that caused one of the warheads in the pallet to detonate. This explosion caused an adjacent warhead to explode sympathetically. These simultaneous explosions severely damaged twelve of the thirteen other warheads in the pallet, and caused their contents to be splashed on and around the igloo apron.

The initial reports from the workers at the site are only that an explosion occurred in the pallet of rockets, that liquid agent is seen all over the igloo apron, and that monitors in and around the accident site indicate high concentrations of agent vapors.

When the Army first responders arrive at the accident site fifteen minutes later, they observe and report that two rocket warheads detonated, twelve rocket warheads were 
so damaged that they lost their contents of liquid agent, and one rocket was not damaged at all. Approximately forty minutes after the accident, the first responders report that the monitor readings in and around the accident site are dropping off. At about forty-five minutes after the accident, the first responders report that with the exception of one piece of equipment, a combination of absorbent materials and decontaminating solutions were applied in and around the accident site. As soon as this was done, the monitor readings in and around the site dropped precipitously, but not to zero. One large piece of equipment that has not yet been decontaminated at the accident site is reported to have the equivalent of approximately sixty square feet of surface area still wet with liquid agent. Due to safety and operational concerns, the first responders report that they will not be able to decontaminate this piece of equipment for an additional hour.

Figure 1 below summarizes the meteorological conditions that are assumed to have existed during the entire duration of the agent release for this case study.

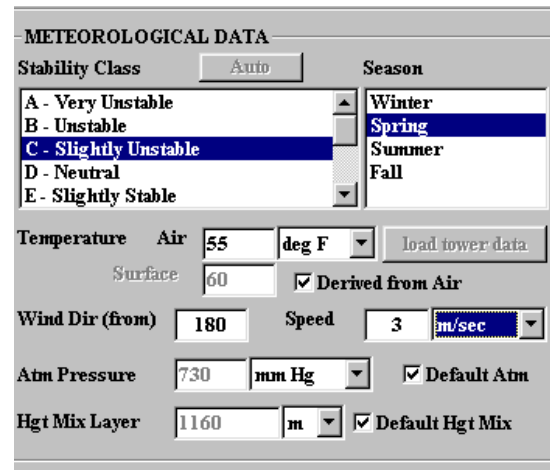

Figure 1. Meteorological conditions assumed for the case study, as taken from D2PCw.

\section{A.2.2 Hazard Analyses Using D2PCw}

Based on the initial reports from the workers at the site and current CSEPP guidance, Army hazard analysts would immediately assess the hazard by using D2PCw to run the Maximum Credible Event (MCE) scenario that two rocket warheads exploded and thirteen leaked. The initial Army protective action recommendation (PAR) and the on-post and off-post protective action decision (PAD) to evacuate or SIP would be based on this initial hazard assessment. For the purposes of this case study, we will assume that the hazard wedge is contained within one off-post emergency planning sub-zone, and that both the PAR and the PAD were that all persons in this sub-zone should SIP immediately. 


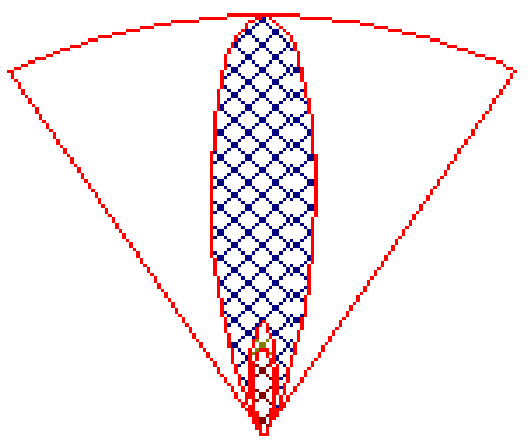

Source Map Scale 1:500,000 Zoom Level 1:1

Figure 2. Initial assessment from D2PCw for this scenario. The length of the hazard wedge is $\sim 6.7 \mathrm{~km}$.

The cigar shaped plume in the hazard wedge produced by D2PCw (see Figure 2) represents the area where the $\mathrm{D} 2 \mathrm{PCw}$ dispersion model predicts some toxic effects for unprotected persons who remain outside at the same point within the wedge until the toxic cloud passes them or dissipates. The smaller cigar shaped areas within the hazard wedge represents areas where there is the potential for fatal exposure. In order to account for the potential for plume meander, the plume is assumed to be somewhere within the hazard wedge. Due to the uncertainty of the location of the plume within the hazard wedge, the centerline concentration of the plume is assumed to exist within the hazard wedge and all decisions are made with this assumption in mind. Therefore, for all practical purposes, the cigar shaped plume can be ignored, and all decisions and observations should focus on arcs within the hazard wedge that represents the toxic thresholds of concern. 
The time when the plume arrives at and departs from a given location is an important aspect of the hazard analysis, and is supposed to be considered when updating PARs and PADs. Where the yellow and red areas meet in Figure 3 below indicates the location of the tail of the plume, based upon the initial hazard assessment, at eighty minutes after the initial release. This figure indicates that at about eighty minutes the tail of the plume is at approximately four km downwind from the release.

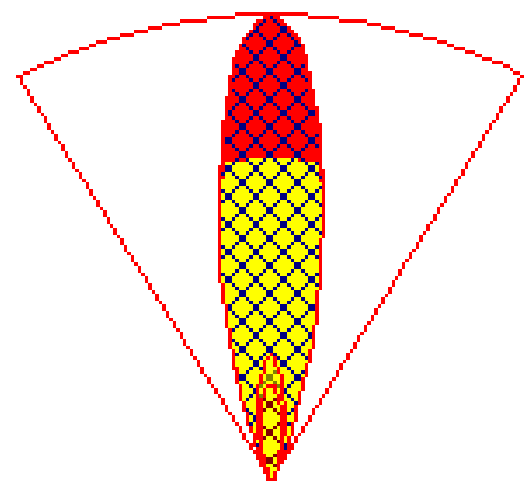

\section{Source Map Scale 1:500,000} Zoom Level 1:1

Figure 3. Location of the tail of the plume eighty minutes after the release, based on the initial assessment.

Any revised PAR or PAD, including any recommendation or decision related to terminating SIP, should be based on the best and most current information from eyewitnesses and monitoring at and near the accident site. For this case study, the hazard analysis is modified as new information is reported from the accident site. Since one round was not damaged, the maximum number of leakers is now known to be twelve, versus the thirteen used in the analysis based on the MCE. Additionally, since monitoring at and around the accident site showed a reduction in agent vapor concentration even before decontaminants were put down, and the D2PCw model predicted a total evaporation time of about forty-five minutes, it would be reasonable to assume that most of the agent in the twelve leakers had evaporated or was neutralized by this time. Finally, the hazard analyst would likely consider the implications of the remaining contaminated piece of equipment with the sixty square foot equivalent puddle in subsequent analysis. 
Figure 4 below shows the revised hazard assessment, based on the updated monitoring and observational data.

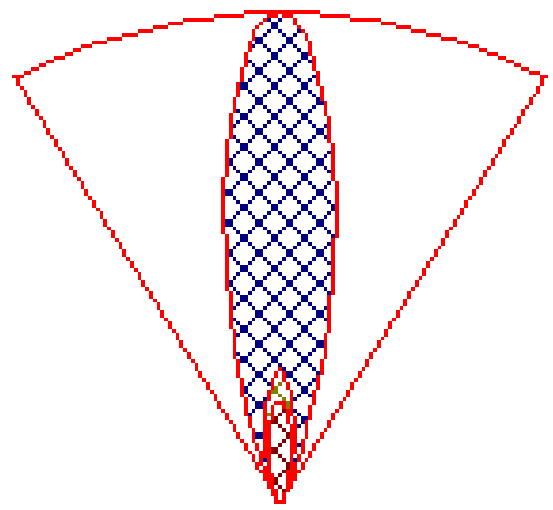

Figure 4. Revised assessment from D2PCw for this scenario. The length of the hazard wedge is $\sim 6.3 \mathrm{~km}$. 
Figure 5 below shows the location of the tail of the plume approximately $3.5 \mathrm{~km}$ from the point of release at 130 minutes after the initial event. While the overall hazard area for this revised assessment is a little smaller than the initial assessment, the plume tail time is significantly longer. If the contaminated piece of equipment were ignored in the revised assessment, then the plume tail times in the revised assessment would be similar to the plume tail times in the initial assessment.

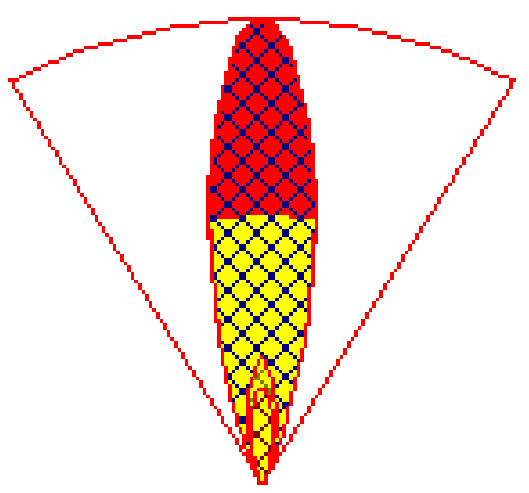

Source Map Scale 1:500,000 Zoom Level 1:1

Figure 5. Location of the tail of the plume 130 minutes after the release based on the revised assessment.

With the tools that are currently available to the hazard analysts, the decision to terminate SIP might be based on when the predicted tail of the plume leaves the area in the hazard wedge. For the initial assessment run, this time is approximately ninety-four minutes after the initial event, and for the revised assessment this time is approximately 148 minutes after the initial event. Compare this assessment with the products of TSIP described next. 


\section{A.2.3 Describing the Scenario in TSIP}

There are three data entry views or tabs in the TSIP graphical user interface. These are:

- $\quad$ Model tab.

- $\quad$ Shelter tab.

- Display tab.

\section{A.2.3.1 Model Tab}

The Model tab includes those parameters associated with the meteorology and the agent source term (i.e., quantity of agent released as a function of time). All of the data that is considered in the Model tab could potentially come from either the D2PCw/PARDOS model inputs (i.e., the meteorological parameters) or the D2PCw/PARDOS model outputs (i.e., source strength as a function of time and plume concentrations as a function of time). Some minor modifications to the PARDOS might be needed to explicitly calculate the plume concentration as a function of time data. If the TSIP concept were integrated into D2PCw/PARDOS then this data would not need to be entered to do the TSIP analysis. In its current form, all but the plume concentration as a function of time data can be obtained from the D2PCw/PARDOS model (inputs or outputs). Since the raw data that describes the plume concentration history is not directly available from D2PCw/PARDOS, TSIP has its own built-in dispersion model. Note that the results of the TSIP dispersion model do differ slightly from the D2PCw/PARDOS dispersion results, but these differences do not impact the use of the TSIP to prove the concept.

If any of the controls in the Model tab are changed, the dispersion model must be rerun. The button labeled "Run Dispersion Model" is enabled whenever the model needs to be rerun. It typically takes a few seconds to run.

Figure 6 on the next page illustrates the parameters that need to be described in the Model tab of TSIP. The meteorological information that is required for TSIP in this case study includes the wind speed (three $\mathrm{m} / \mathrm{s}$ ) and stability class $(\mathrm{C})$, the same as shown in Figure 1 above. 


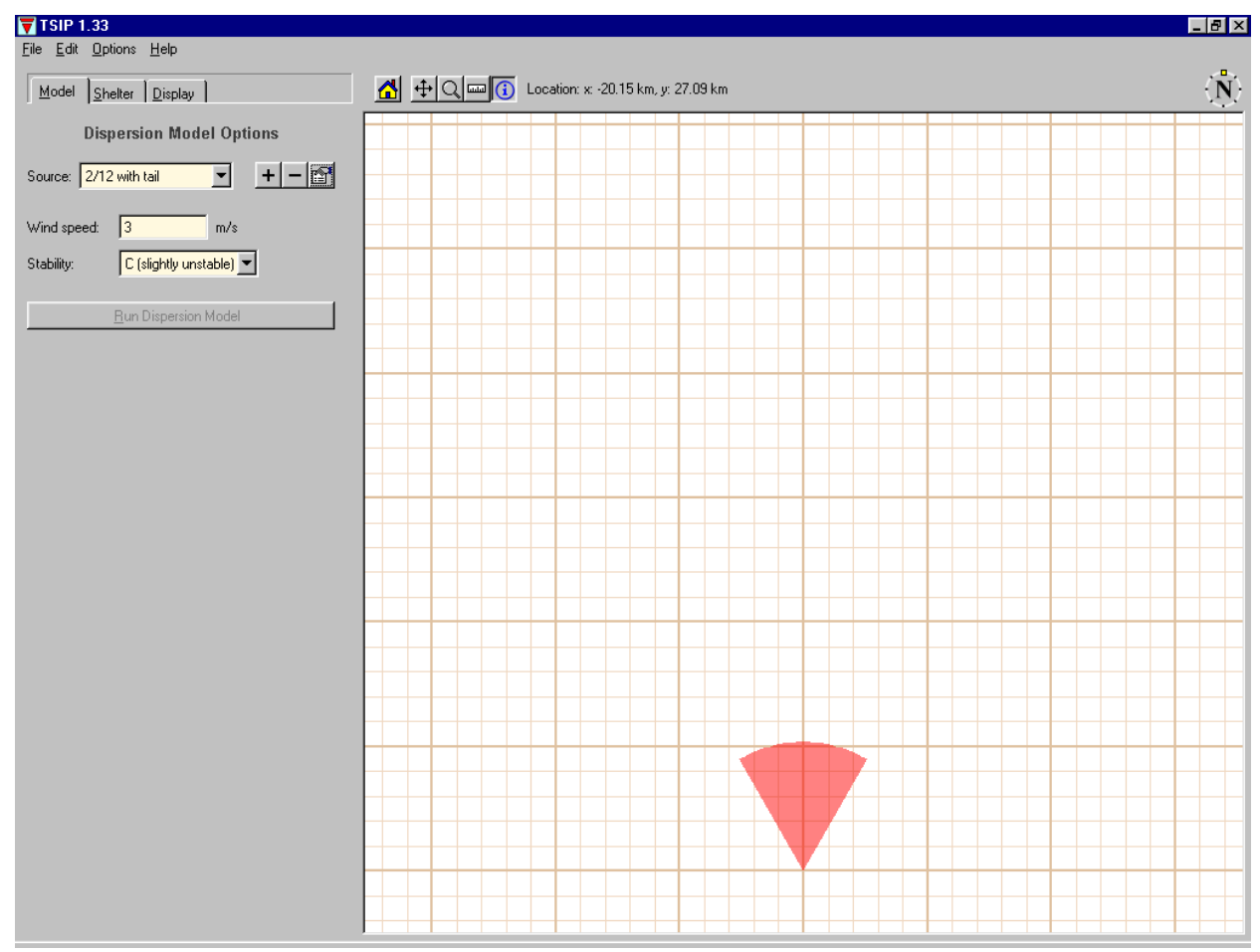

Figure 6. TSIP Model tab

Based on the results of the revised hazard analysis, the source term as a function of time as predicted from D2PCw, is given in Figure 7 (linear scale) and Figure 8 (log scale) below.

\section{Agent Release Rate over Time}

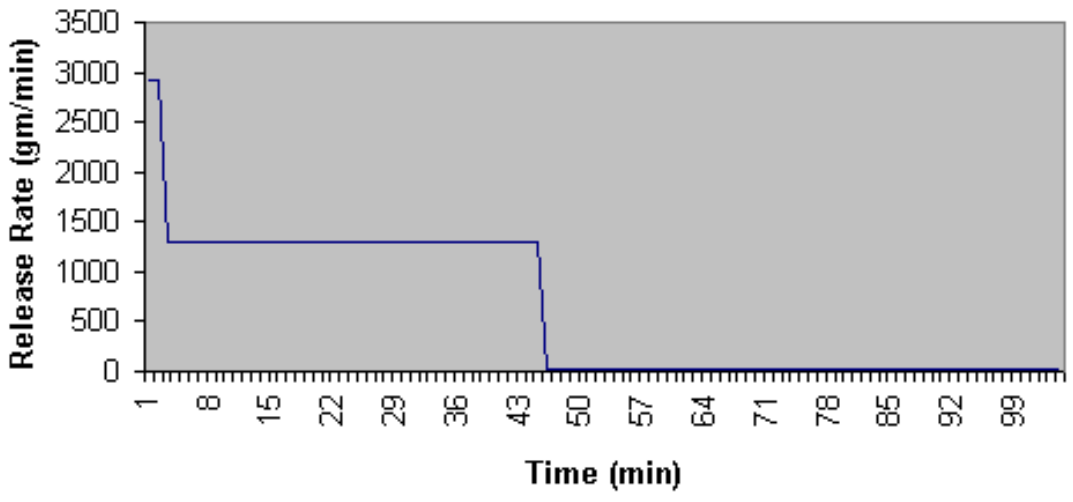

Figure 7. Release rate as a function of time for the revised assessment (linear scale). 
Agent Release Rate over Time

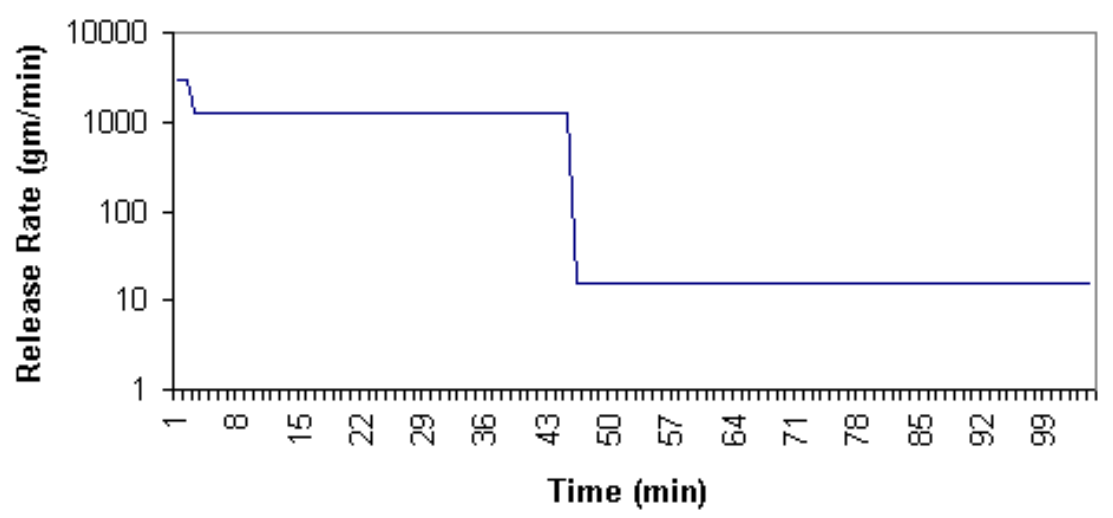

Figure 8. Release rate as a function of time for the revised assessment (log scale).

The drop-down list control labeled Source lets you select the source to use from the library of available sources. By pressing the $[+]$ button, you can add new sources to the library. Press the [-] button to remove a source from the library. Press the button with the picture of the hand and paper to edit a source's options, which brings up a window called "Edit source options" as shown in Figure 9. When editing a source's mass release rate, enter a list of emission times and mass emitted during that time. Note that the times are the length of the emission period. The data shown in Figure 9 reflects the emission data shown in Figures 7 and 8.

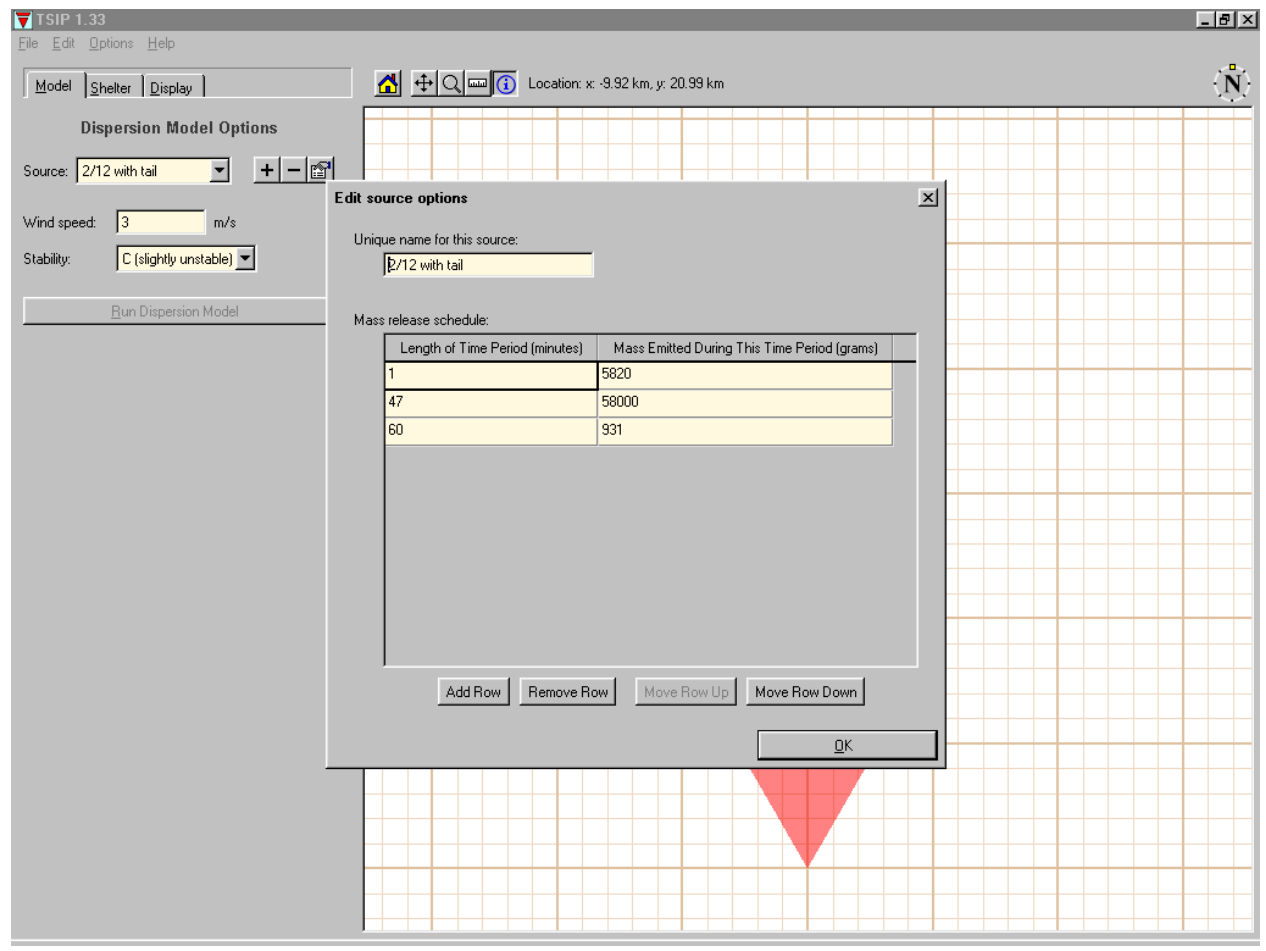

Figure 9. TSIP "Edit source options" window 
Once the data in entered into the Model tab and the "Edit source options" window, the TSIP dispersion model must be run by clicking the "Run Dispersion Model" button. When the dispersion model is finished running, the display to the right will be updated. This display will be discussed in detail below.

\section{A.2.3.2 Shelter Tab}

Figure 10 shows the TSIP Shelter tab. Most of the unique features of the TSIP concept are reflected in this tab. The Shelter tab allows variables that are related to shelters (i.e., infiltration and ventilation air exchange rates) and the sheltering action taken (in minutes after the initial release) to be entered into the TSIP. The sheltering action related variables include:

- $\quad$ Time Entered Shelter.

- $\quad$ Time Ventilated Shelter.

- $\quad$ Time Exited Shelter.

- $\quad$ Time Exited Hazard Area

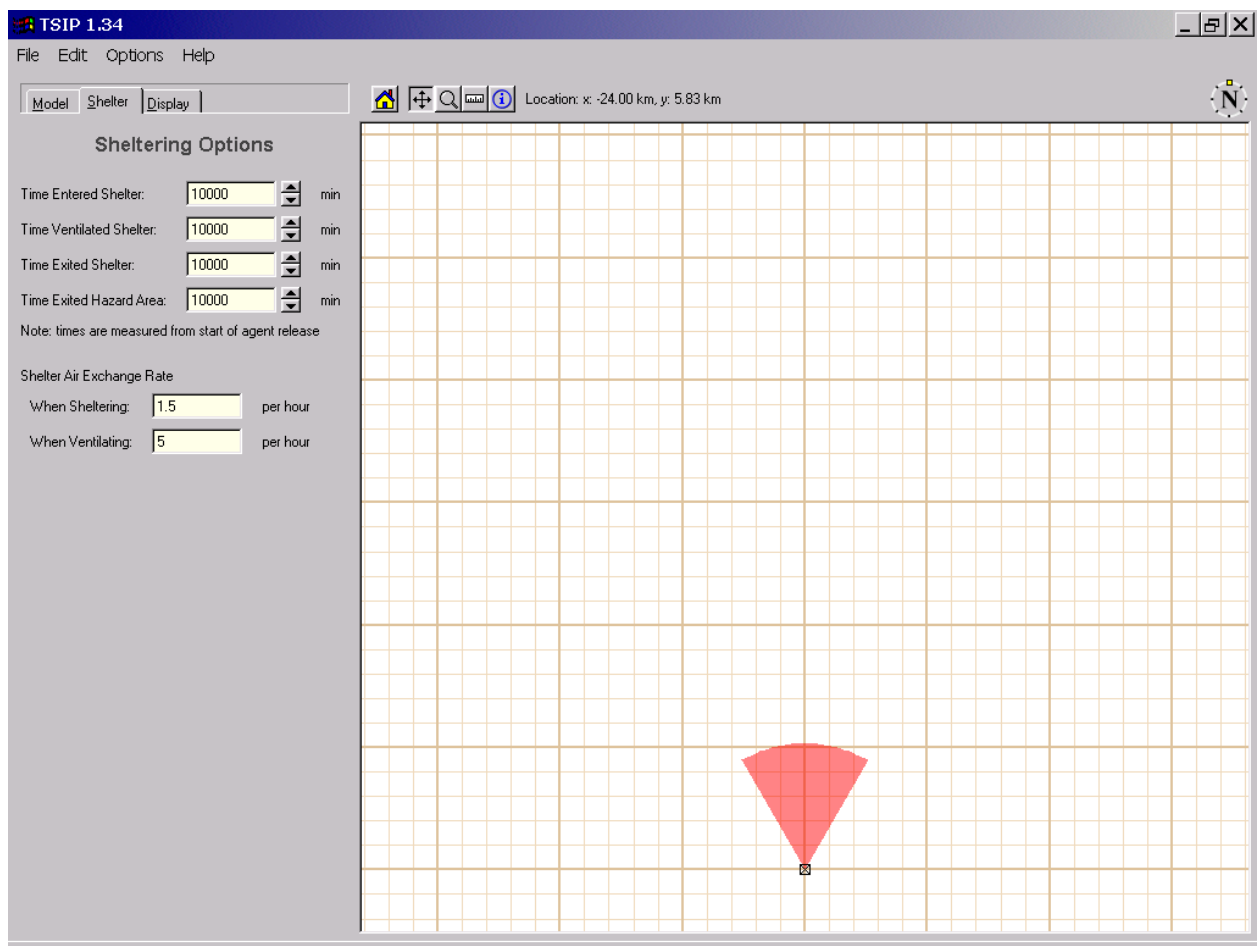

Figure 10. TSIP Shelter tab 
A hazard area display that represents the same information that is given by the $\mathrm{D} 2 \mathrm{PCw} / \mathrm{PARDOS}$ hazard wedge can be achieved by setting all sheltering options to 10000. See Figure 10 on the preceding page. This set of values represents that the population remains outside during the entire event and does not take shelter nor leave the hazard area. Note that if the population does not shelter, then the "Time Ventilated Shelter" as well as the air infiltration and air ventilation rates do not matter.

Adjusting these variables allows the user to see how different sheltering actions will affect the displayed hazard area. As a general rule for a given scenario, the time the population enters the shelter would be established during the early phase of the response (e.g., 20 minutes in this case study). ${ }^{1}$ The time the population ventilates shelters, exits from shelters, and/or relocates to an area outside of the hazard area, would be manipulated in the model to find a sheltering strategy combination that produces the minimum hazard area at the toxic effect of concern. Once a reasonable time/minimum area was found, sensitivity studies could quickly be done using different shelter infiltration rates (e.g., 1.5 air changes per hour $(\mathrm{ACH})$ versus $0.5 \mathrm{ACH})$ to see if the optimum time to exit the shelter varied according to different shelter types.

\section{A.2.3.3 Display $\mathrm{Tab}$}

Figure 11 on the next page shows the TSIP Display tab. Once the dispersion model has been run, the controls in the Display tab control how the results are displayed. The display will be automatically updated whenever any of these controls are changed

The Display tab allows the user to select the toxic effect of concern (i.e., No Effects, No Deaths, $1 \%$ Lethality, AEGL-2 ${ }^{2}$, or AEGL-3) that will be shown in the display on the right. Since the toxic effect of concern in Figure 11 is the threshold of adverse effects to unprotected persons in the hazard wedge, and considering the information previously entered into the Model and Shelter tabs, the hazard wedge shown in this figure represents the TSIP equivalent of the D2PCw hazard wedge. Figure 12, on the other hand, shows the TSIP effects of switching the level of concern to the threshold where fatalities might occur, with no change to the Model or Shelter information in the other tabs.

\footnotetext{
${ }^{1}$ This case study assumes that: the chemical event was detected and reported immediately; the Army decided on a PAR to SIP and sent this to the off-post warning point within five to ten minutes after the event was detected; the off-post officials decided on a PAD to SIP and broadcast an appropriate alert and notification within eight minutes after the warning point was notified; and an educated public took appropriate shelter within two minutes after notification. The approximate time it took to accomplish the above tasks during the actual emergency response should be considered when this methodology is used for response decision-making, and the Time Entered Shelter adjusted accordingly.

2 The Army/CSEPP is considering using the AEGL-2 and AEGL-3 values in place of the No Effects, No Deaths, and 1\% Lethality dosages, after the EPA comment and approval process is completed.
} 


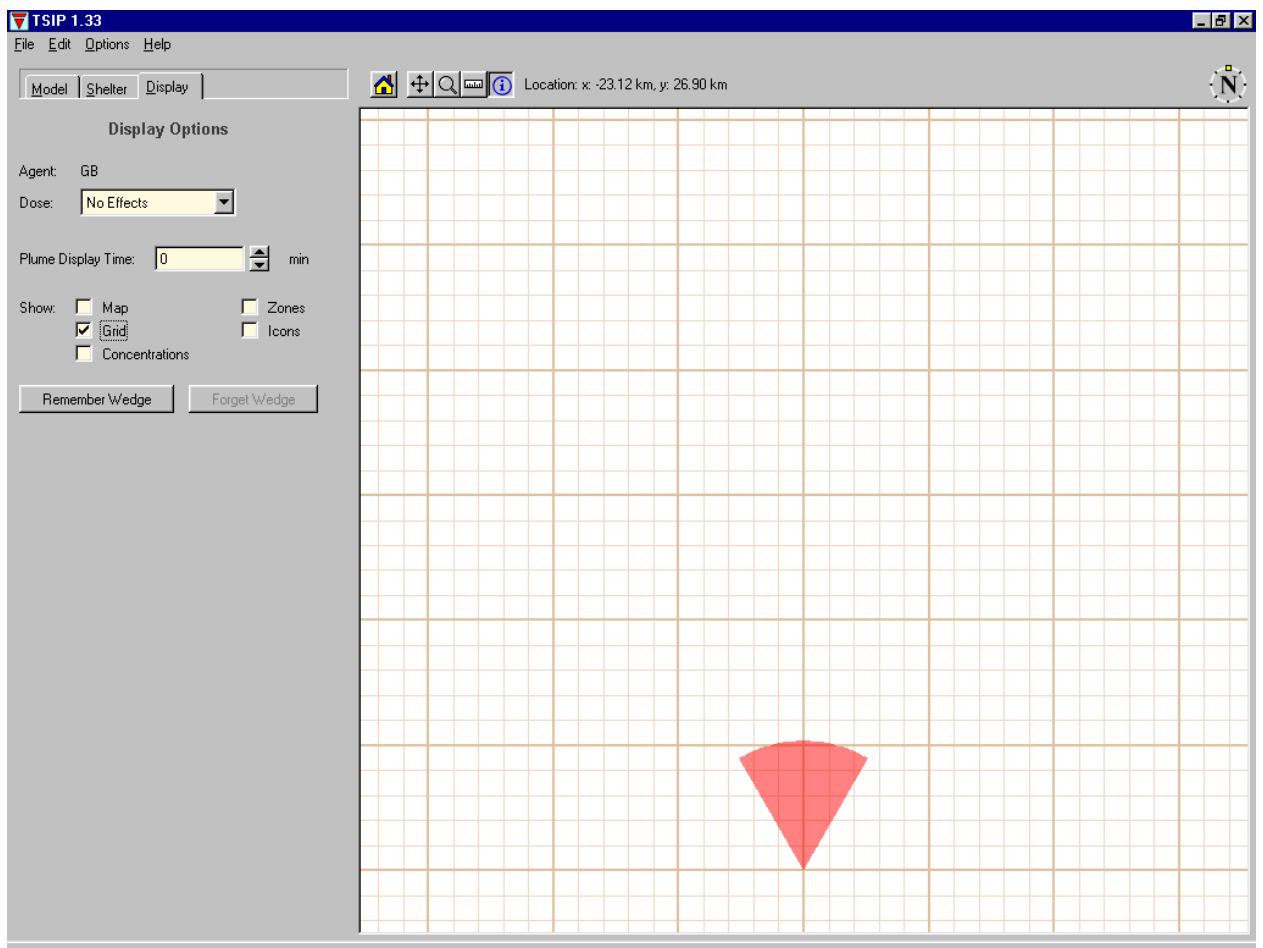

Figure 11. TSIP Display tab for the threshold level of some adverse effects to unprotected persons anywhere in the hazard wedge.

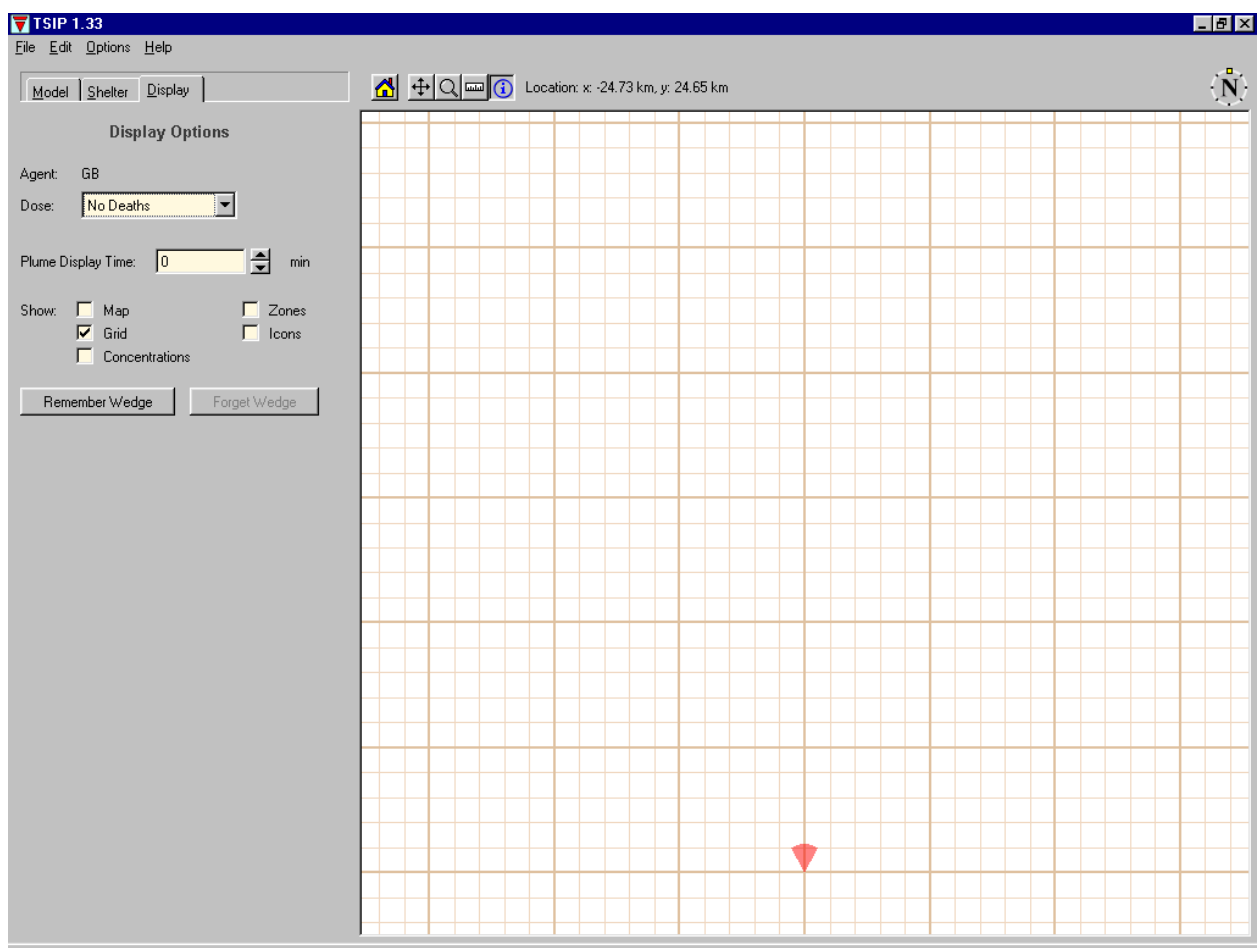

Figure 12. TSIP Display tab for the threshold level where fatalities might occur. 
The location of the plume with respect to distance traveled within the hazard wedge can be shown on the map by using the Plume Display Time. A red bar will represent the location of the plume when the Plume Display Time is set to a time when the plume will be present in the area of interest. Use the Plume Display Time control to change the time at which the plume is displayed. To hide the plume, set the Plume Display Time to zero. Figures illustrating the plume display and some of the other display options will be presented later in this appendix.

Additional information can be displayed on the map using the check boxes in the Show section. The Map and Zones check boxes provide a sample background map and set of sub-zones, respectively. If you check the Grid box a checkerboard grid is displayed, as shown in Figure 11 (as well as all other TSIP screen captures in this appendix). Major grid lines are spaced every five $\mathrm{km}$. Minor grid lines are spaced every one $\mathrm{km}$. If you check the Icon box a square with an $\mathrm{X}$ in it will appear to mark the location of the source. If the Concentrations box is checked, then both the outside and inside (as in inside a shelter) centerline concentrations will be graphically displayed along the hazard wedge centerline. Also, if you checked the Concentrations box, a tree symbol will appear next to the outside centerline concentration indicator bar, and a house symbol will appear next to the inside centerline concentration indicator bar.

Finally, pressing the Remember Wedge button will cause the currently displayed hazard wedge to be remembered on the screen. You can then change the options to cause another wedge to appear on the screen. This allows you to compare the two wedges. Press the Forget Wedge button to erase the saved wedge. 


\section{A.2.4 Exploring Sheltering Options Where Fatalities Might Occur}

At this point, we will take the information that has been entered into TSIP (i.e., the revised assessment for our case study displaying the threshold level for fatalities with no sheltering-related actions taken) as the base line of our analysis. Zooming in on the hazard wedge, and then using the Remember Wedge feature from the Display tab, the outline of this baseline hazard is shown in Figure 13 below.

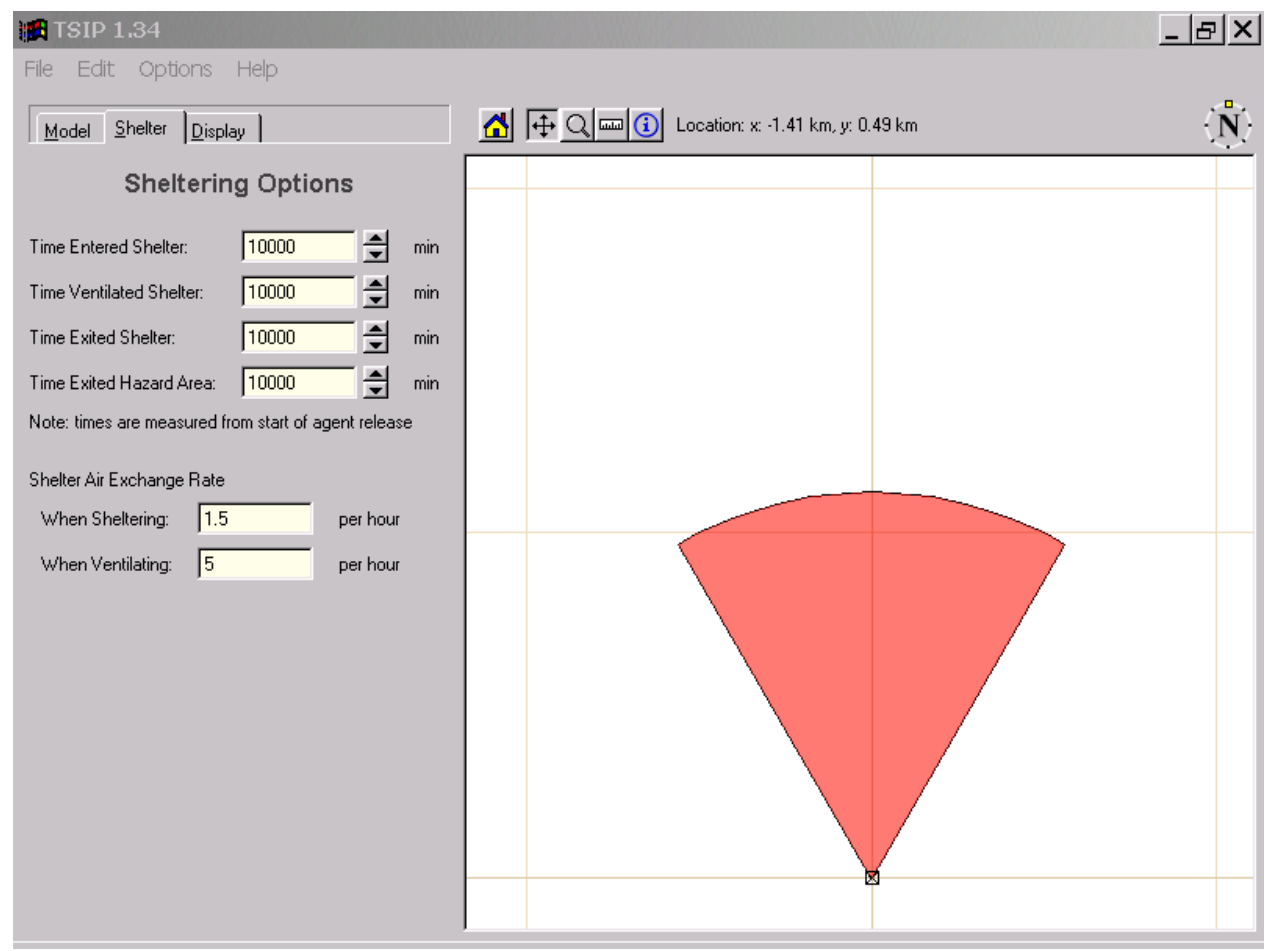

Figure 13. TSIP Display tab at the threshold for fatalities, baseline analysis.

Note that Figure 13 shows the Shelter tab information, since it is from this tab that we will adjust the variables to see how different sheltering actions will affect the displayed hazard area. As a general rule for a given scenario, the time the population enters the shelter would be determined first. Then the time the population ventilates shelters, exits from shelters, and/or relocates to an area outside of the hazard area, is modified to find a sheltering strategy that gives the minimum hazard area. Once a reasonable time/minimum area was found, sensitivity studies could quickly be done using different shelter infiltration rates (e.g., $1.5 \mathrm{ACH}$ versus $0.5 \mathrm{ACH}$ ) to see if, for example, the optimum time to exit the shelter was different for different shelter types.

For this case study we will assume that the population has taken shelter by twenty minutes after the initial release. Additionally, we will ignore the option of ventilating the shelter. Note that setting the variable "Time Ventilated Shelter" to a very large number (e.g., 10000 minutes) will effectively mean that the shelter is never ventilated. For our case study, we will adjust only the Time Exited Shelter and the air infiltration rate. We will start out with an assumed air infiltration rate of $1.5 \mathrm{ACH}$. 


\section{A.2.4.1 Adjusting the Time to Exit Shelter}

Figure 14 below shows a sheltering strategy where the population enters their shelters at twenty minutes after the release and then exits from their shelters at twentyfive minutes after the release. The red area is the hazard area for this sheltering strategy and the area outlined in black is the baseline hazard based on no sheltering-related actions taken. This figure shows that by being in shelters between twenty and twenty-five minutes after the release (i.e., a total of five minutes in shelter) the population is afforded some protection that is greater than not taking any shelter at all.

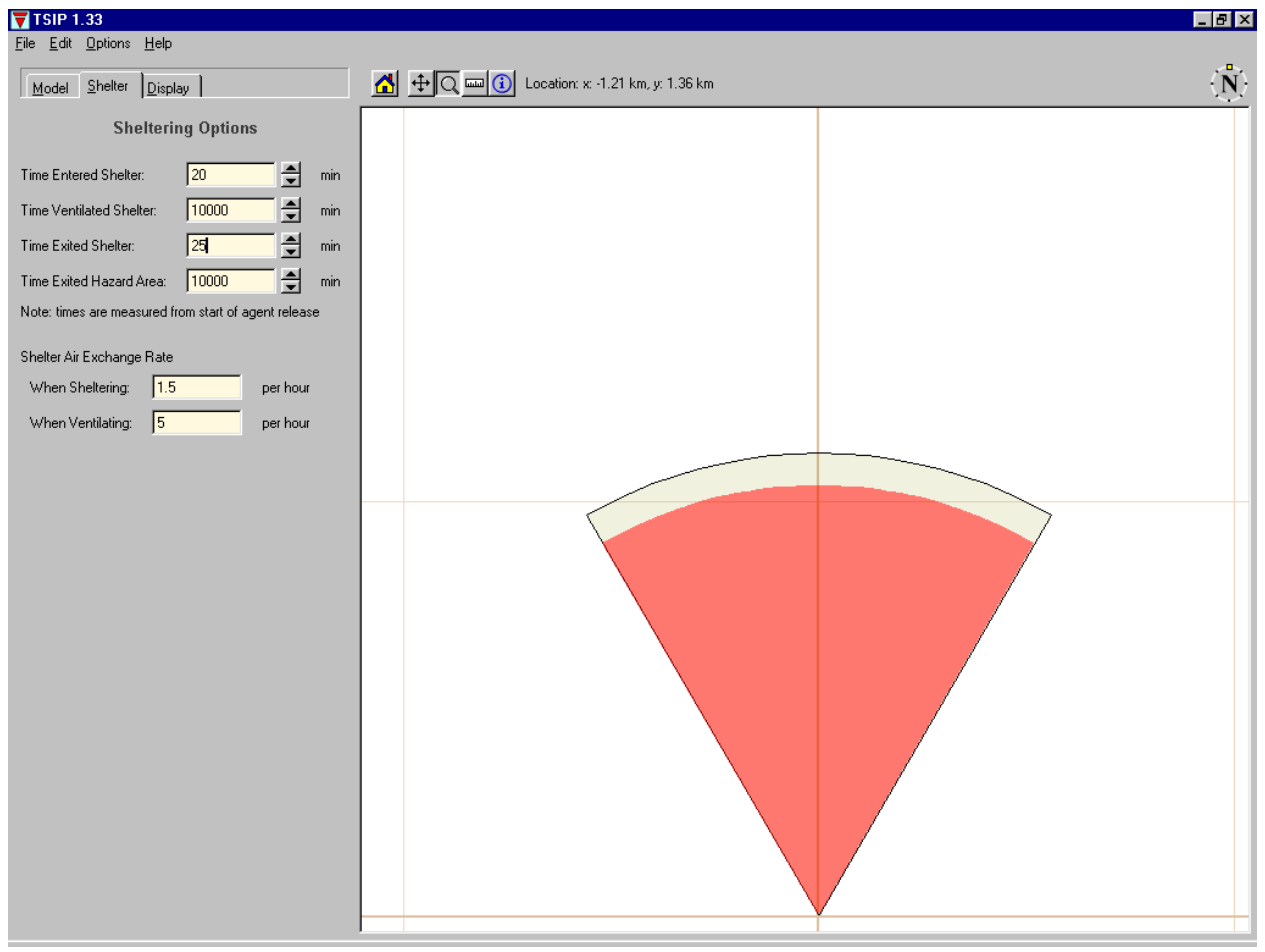

Figure 14. TSIP Shelter tab at the threshold for fatalities, when sheltering begins after twenty minutes and concludes after twenty-five minutes. 
If the population were to exit their shelters at forty minutes instead of at twentyfive minutes after the release the hazard area is reduced even further, as shown in Figure 15 below.

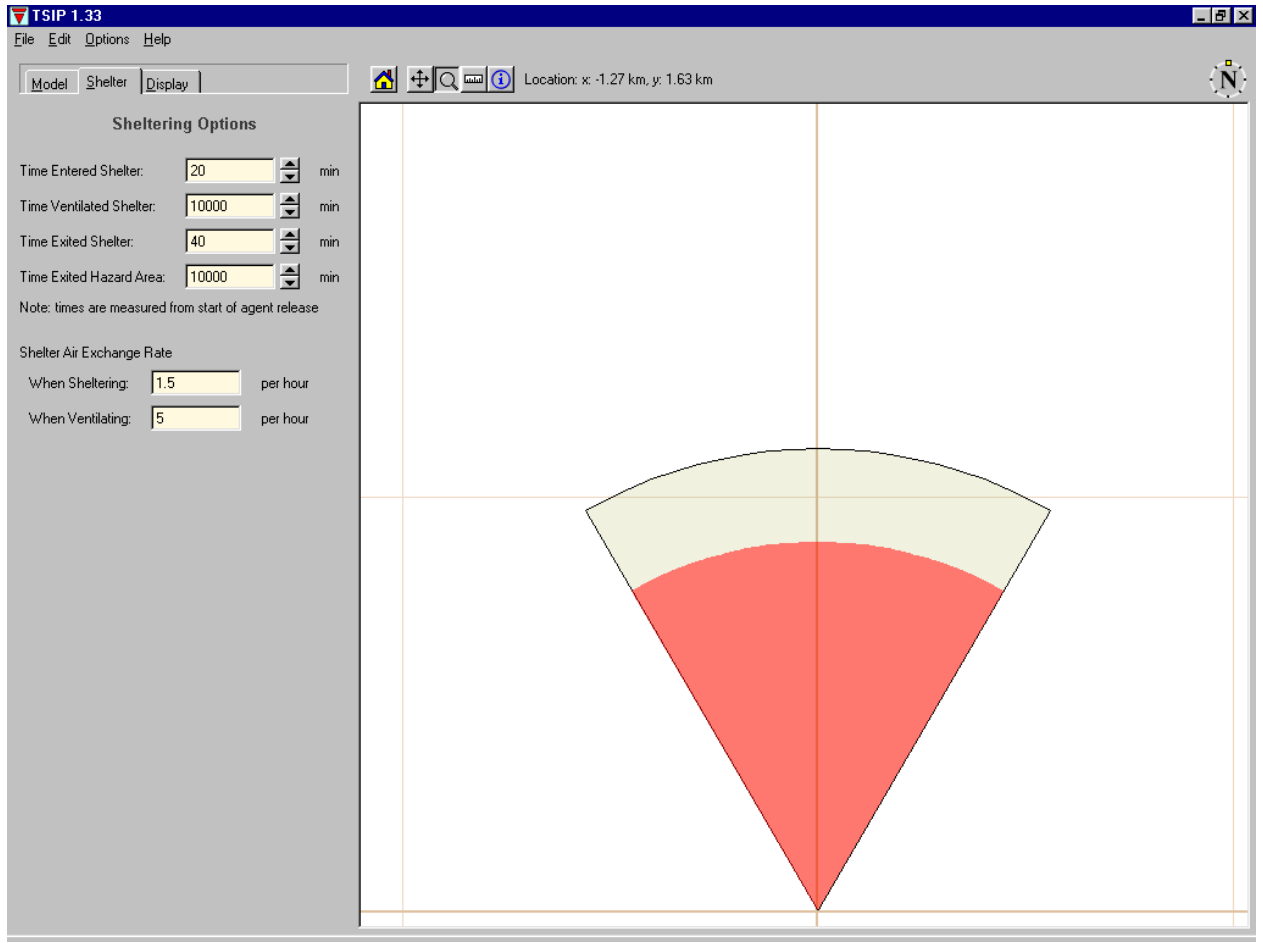

Figure 15. TSIP Shelter tab at the threshold for fatalities, when sheltering begins after twenty minutes and concludes after forty minutes. 
If the population were to exit their shelters at fifty-five minutes instead of at forty minutes after the release, the hazard area is reduced even more, as shown in Figure 16 below. TSIP shows that by selecting a Time Exited Shelter of between fifty and fiftyseven minutes the hazard area is minimized. Values below fifty minutes (i.e., exiting shelters too soon) and values above fifty-seven minutes (i.e., exiting shelters too late) cause the hazard area to increase.

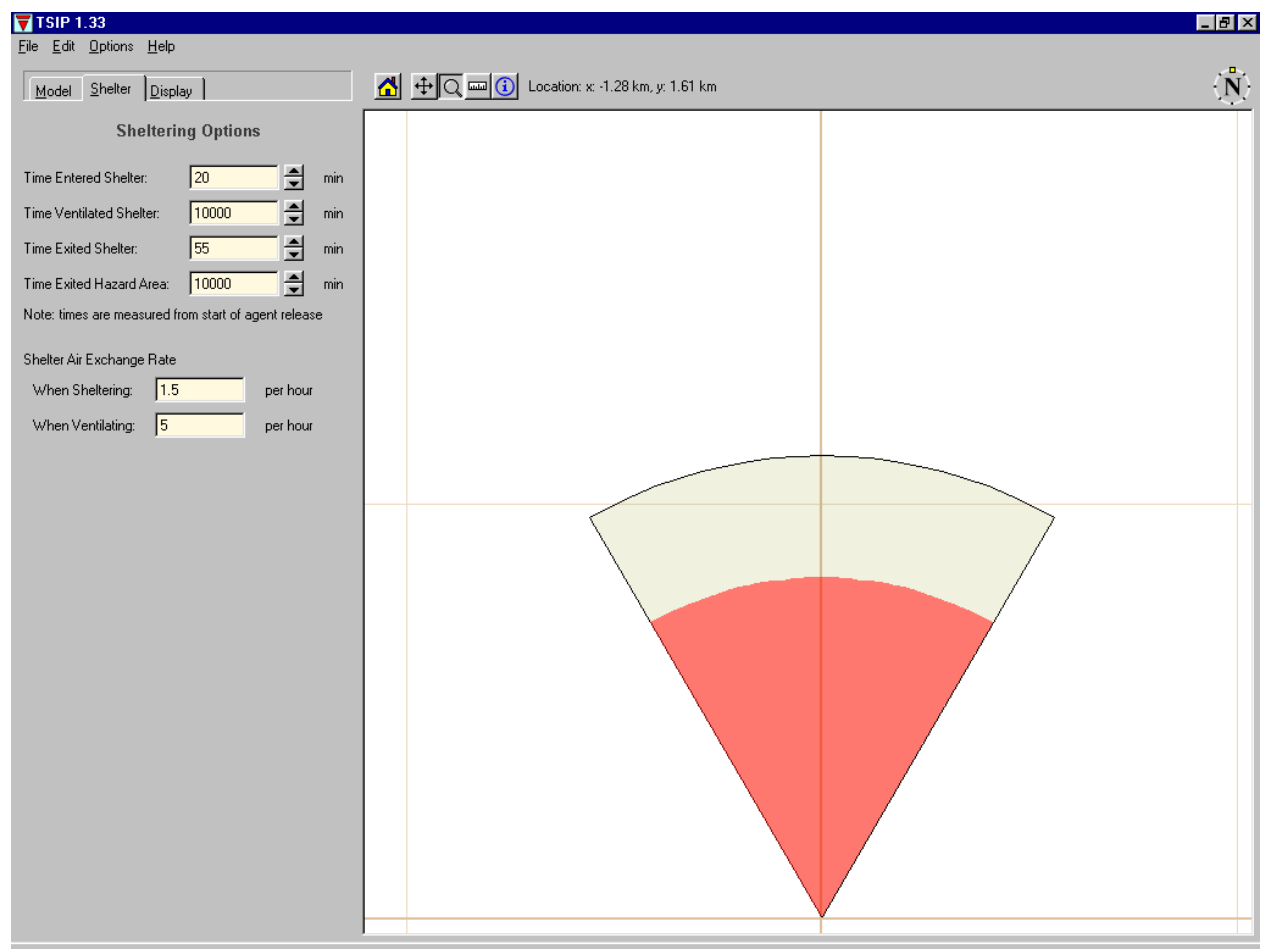

Figure 16. TSIP Shelter tab at the threshold for fatalities, when sheltering begins after twenty minutes and concludes after fifty-five minutes. This displays the minimum area that can be obtained by varying the Time Exited Shelter.

Figures 17, 18 and 19 show the effects of exiting shelters too late for times of sixty-five minutes, eighty-five minutes and 120 minutes after the initial release.

Interestingly, exiting shelters eighty-five minutes after the initial release results in the same size area where fatalities might occur had no one in that area sheltered in the first place. By remaining in shelters beyond eighty-five minutes the potential for fatalities will be even greater than the baseline (i.e., never having sheltered) as Figure 19 shows. Note that when remaining in shelters beyond eighty-five minutes the area of potential fatalities is greater than the base-line scenario because the population in that area received significant exposure prior to entering shelters (i.e., during the twenty minutes after the accident before they entered shelters) and an additional significant exposure while in shelters. For this scenario, then, TSIP shows that using plume tail times from D2PCw/PARDOS to decide when and how to end SIP will cause unnecessary toxic exposure regardless of whether the small, lingering hazard from the agent remaining on the piece of equipment is included in the analysis. 


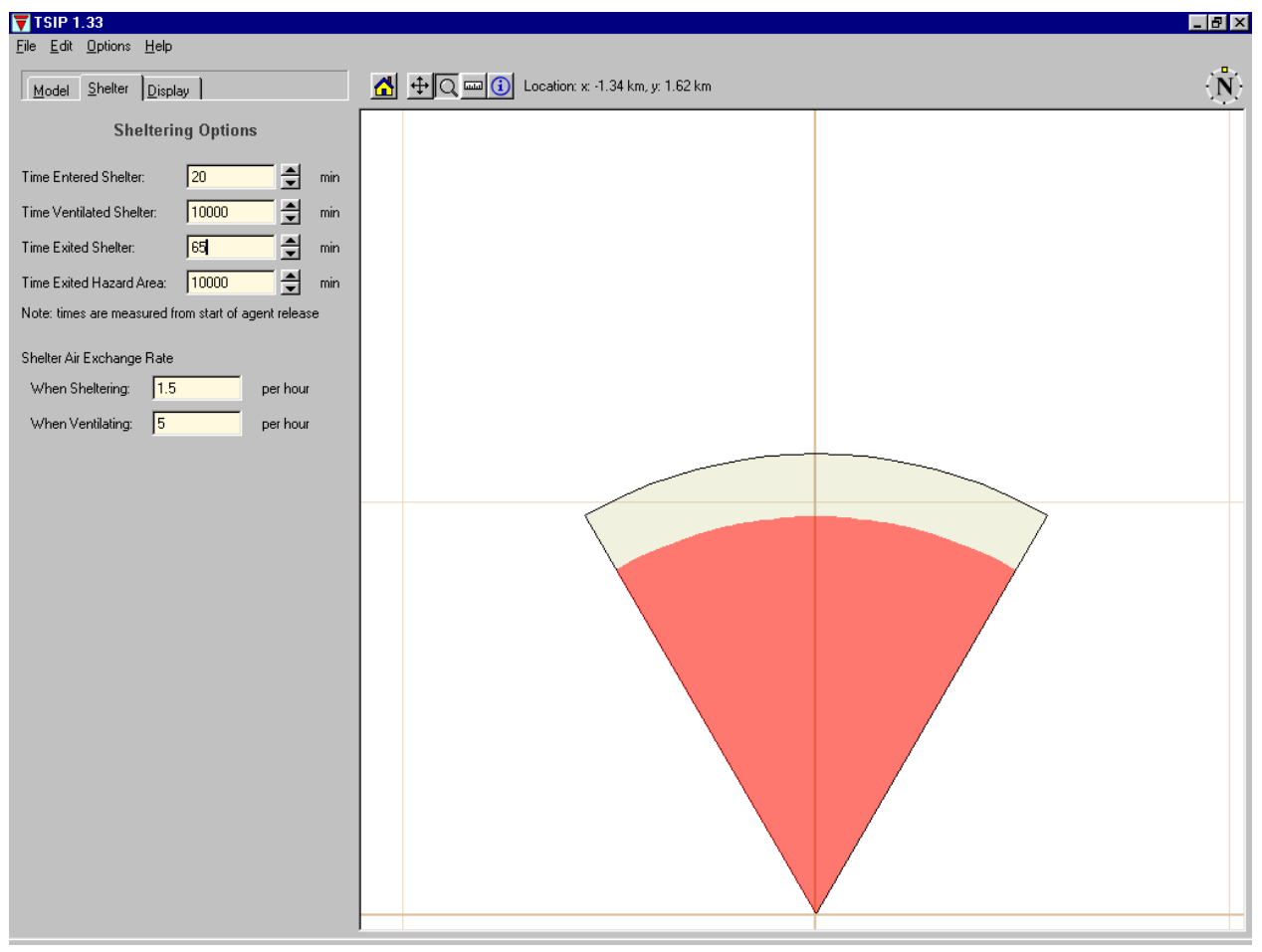

Figure 17. TSIP Shelter tab at the threshold for fatalities, when sheltering begins after twenty minutes and concludes after sixty-five minutes.

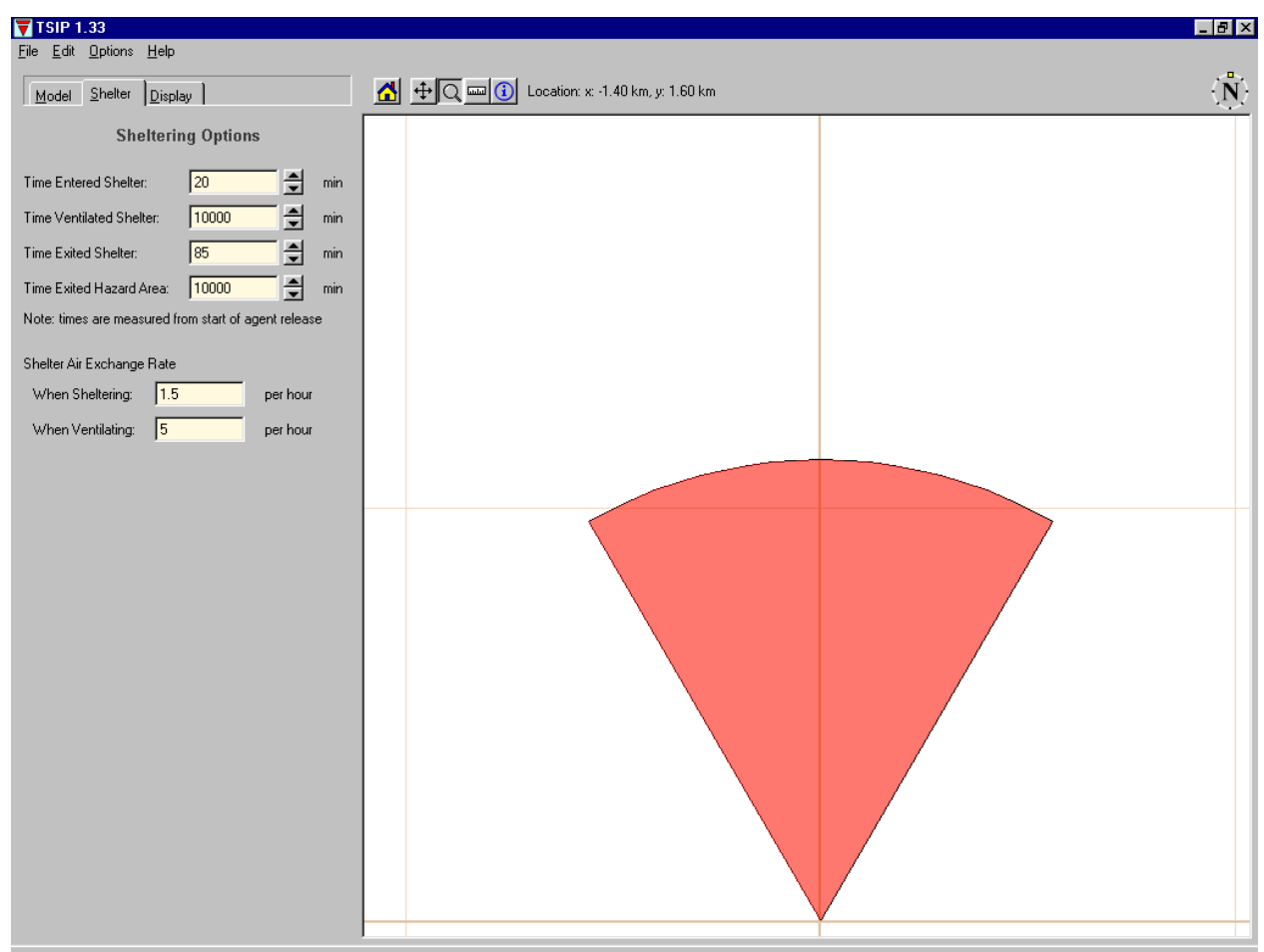

Figure 18. TSIP Shelter tab at the threshold for fatalities, when sheltering begins after twenty minutes and concludes after eighty-five minutes. 


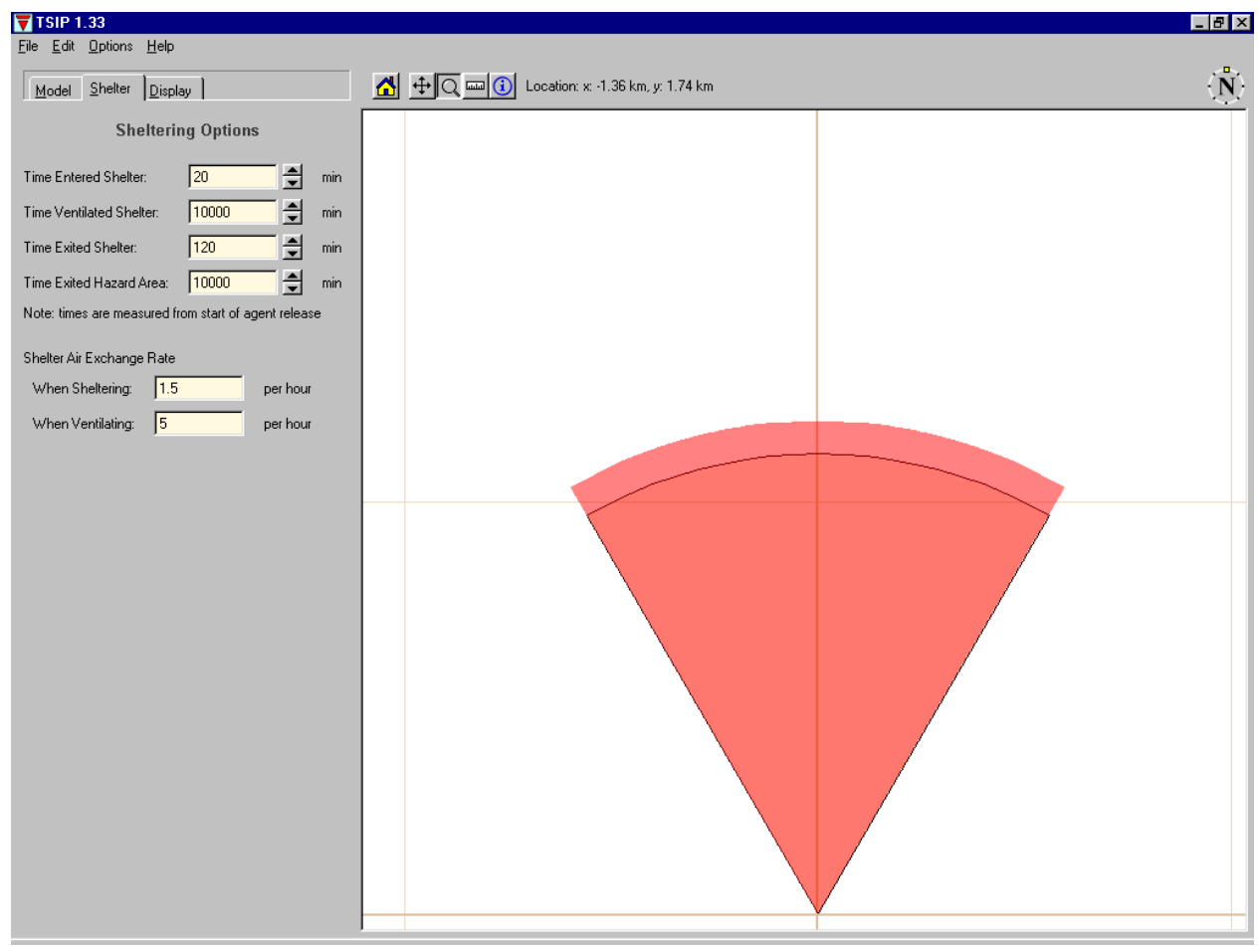

Figure 19. TSIP Shelter tab at the threshold for fatalities, when sheltering begins after twenty minutes and concludes after 120 minutes.

If the hazard analysis is run using AEGLs instead of the linear cumulative dosage model for nerve agent currently used by CSEPP, the action times would potentially differ, but the decision-making process would be the same.

\section{A.2.4.2 Adjusting the Air Infiltration Rate of the Shelter}

So far in this case study we found that the smallest area where fatalities might occur is when the population exits shelters between fifty and fifty-seven minutes after the initial release. This assumed that the population entered shelters twenty minutes after the release and the shelters had an air exchange rate of 1.5 ACH. Now we will investigate how tighter shelters would affect the optimum time to terminate SIP.

If we adjust the shelter air exchange rate from 1.5 to $0.5 \mathrm{ACH}$, and keep all of the other variables the same, TSIP shows that the hazard area of concern is indeed smaller with tighter shelters. See Figure 20. This trend is to be expected. What is not as easy to predict is how much the tighter shelter will affect the optimum terminate SIP time. Recall that it was between fifty and fifty-seven minutes for $1.5 \mathrm{ACH}$ shelters. A quick sensitivity analysis with TSIP, as done in the previous section but not illustrated here with screen captures, shows that the optimum time to terminate SIP for the tighter shelters is between forty-eight and fifty-eight minutes. So, for this case study, the optimum time to exit SIP was not very sensitive to the permeability of shelters, at least between 0.5 and $1.5 \mathrm{ACH}$. 


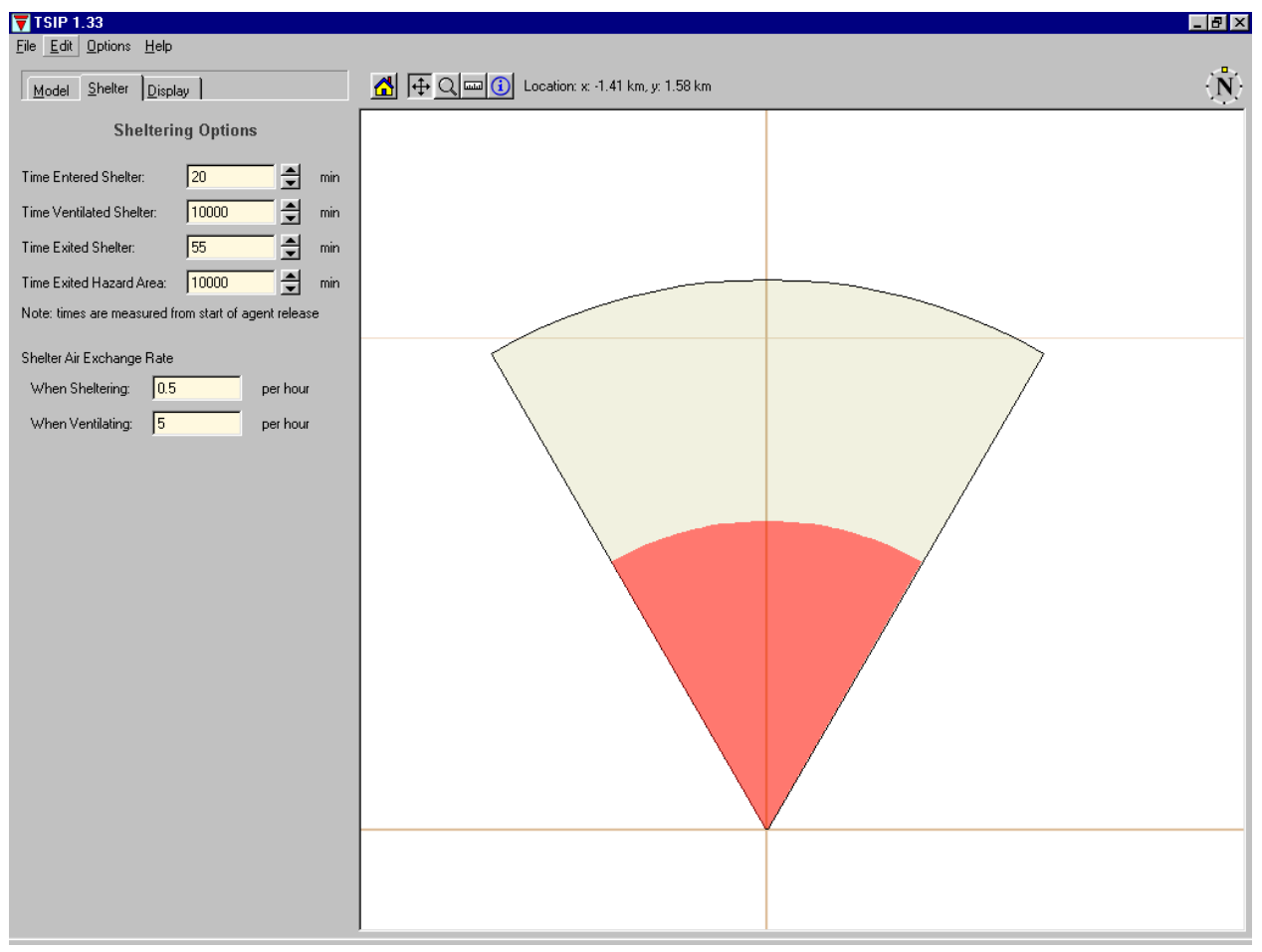

Figure 20. TSIP Shelter tab at the threshold for fatalities, when sheltering begins after twenty minutes and concludes after fifty-five minutes in shelters with $0.5 \mathrm{ACH}$.

\section{A.2.5 Exploring Sheltering Options Where Fatalities Are Not Expected}

After TSIP is used to obtain the best time and way to terminate SIP in areas where fatalities might occur, the same process can be repeated to optimize the termination of SIP in areas in the hazard wedge where toxic effects are possible but fatalities are not expected. This process is not illustrated in this case study. 


\section{A.3 OTHER FEATURES OF TSIP}

There are a few other features of the TSIP model that are noteworthy. These are the Plume Locator, the Concentration Indicator Bars, and the Report Feature.

\section{A.3.1 Plume Locator}

The Plume Display Time, which appears under the Display tab, allows the location of the plume at a give time to be displayed on the map along side the hazard area of concern. This display is familiar to hazard analysts because it is similar in many ways to the PARDOS slices in D2PCw. This plume locator bar does not illustrate relative concentration levels. Rather, it indicates if the hazardous plume exists at any concentration for a given point in time and space. Figure 21 illustrates the plume locator with TSIP.

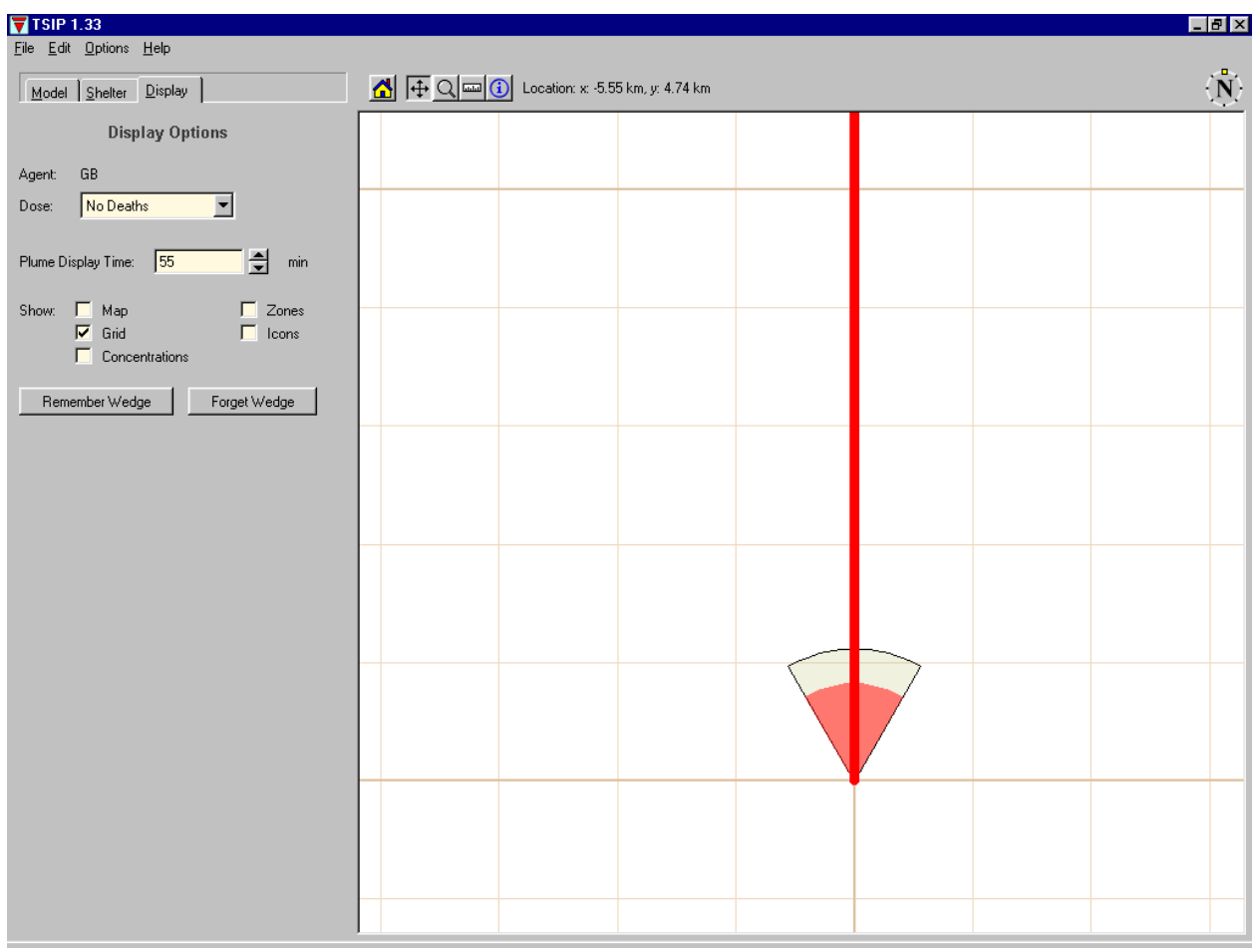

Figure 21. TSIP Display tab with plume indicator shown. 


\section{A.3.2 Concentration Indicator Bars}

If the Concentration box is checked on the Display tab, then the centerline concentrations both outside and inside the shelter will be displayed along the hazard wedge centerline, as shown in Figure 22 below. Outside concentrations are indicated on the left, and inside concentrations are indicated on the right. The concentration are indicated using a logarithmic color scale, ranging from $1 \times 10^{\wedge}-5 \mathrm{mg} / \mathrm{m}^{\wedge} 3$ (black) to $1 \times 10^{\wedge} 1 \mathrm{mg} / \mathrm{m}^{\wedge} 3$ (yellow). The Plume Display Time control is used to change the time at which the concentrations are displayed. This feature of TSIP allows the user to visualize the relative inside and outside concentrations at different times during the release.

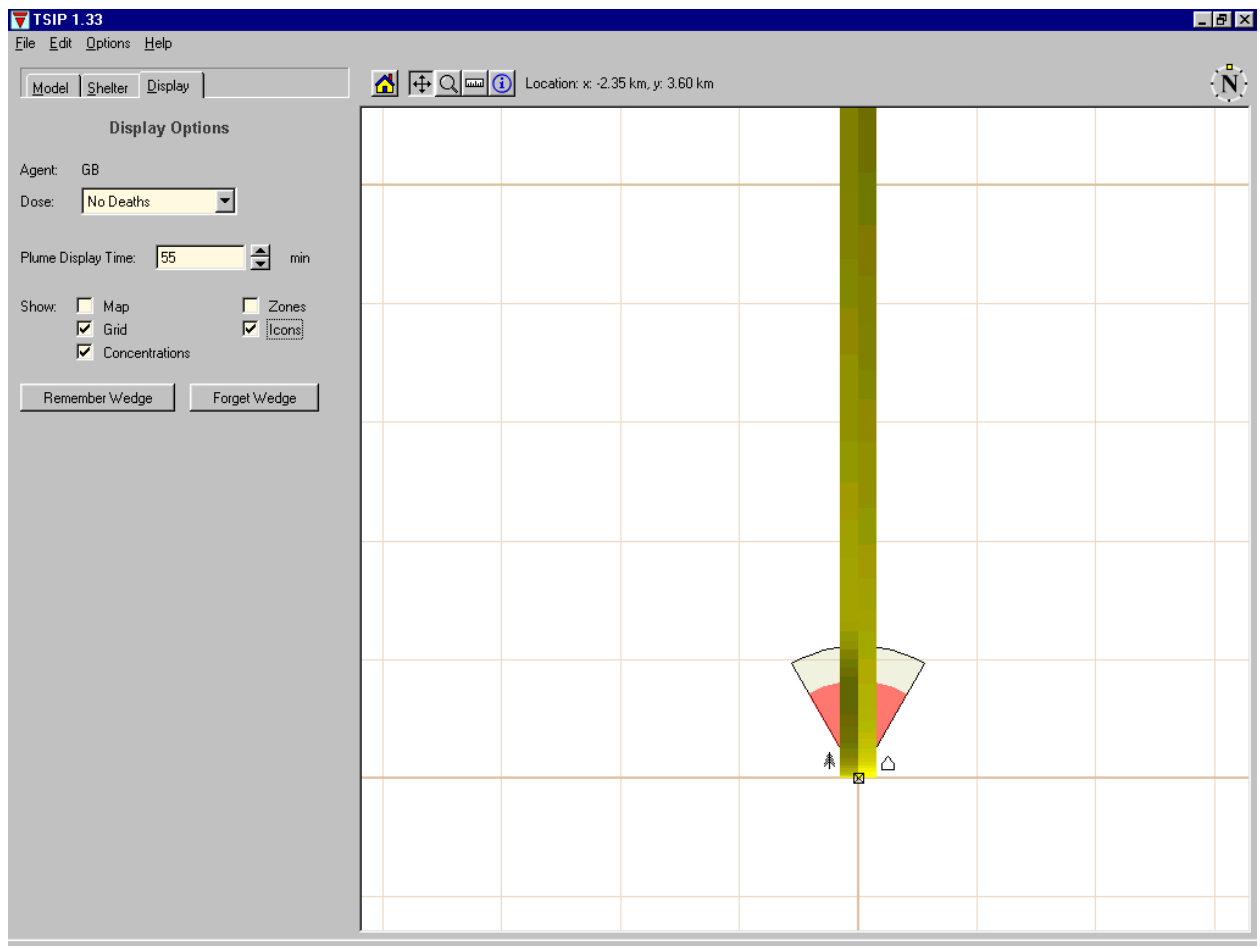

Figure 22. TSIP Display tab showing inside and outside concentration indicator bars. 


\section{A.3.3 Report Feature}

If the information tool bar button (the toolbar button with an "i" inside a circle) is highlighted and then a point within the hazard area is selected, a report summarizing the scenario and concentrations at that distance downwind from the release point will be displayed. See Figures 23, 24, and 25. The top part of the report, Figure 23, summarizes the Model, Sheltering, and Display options.

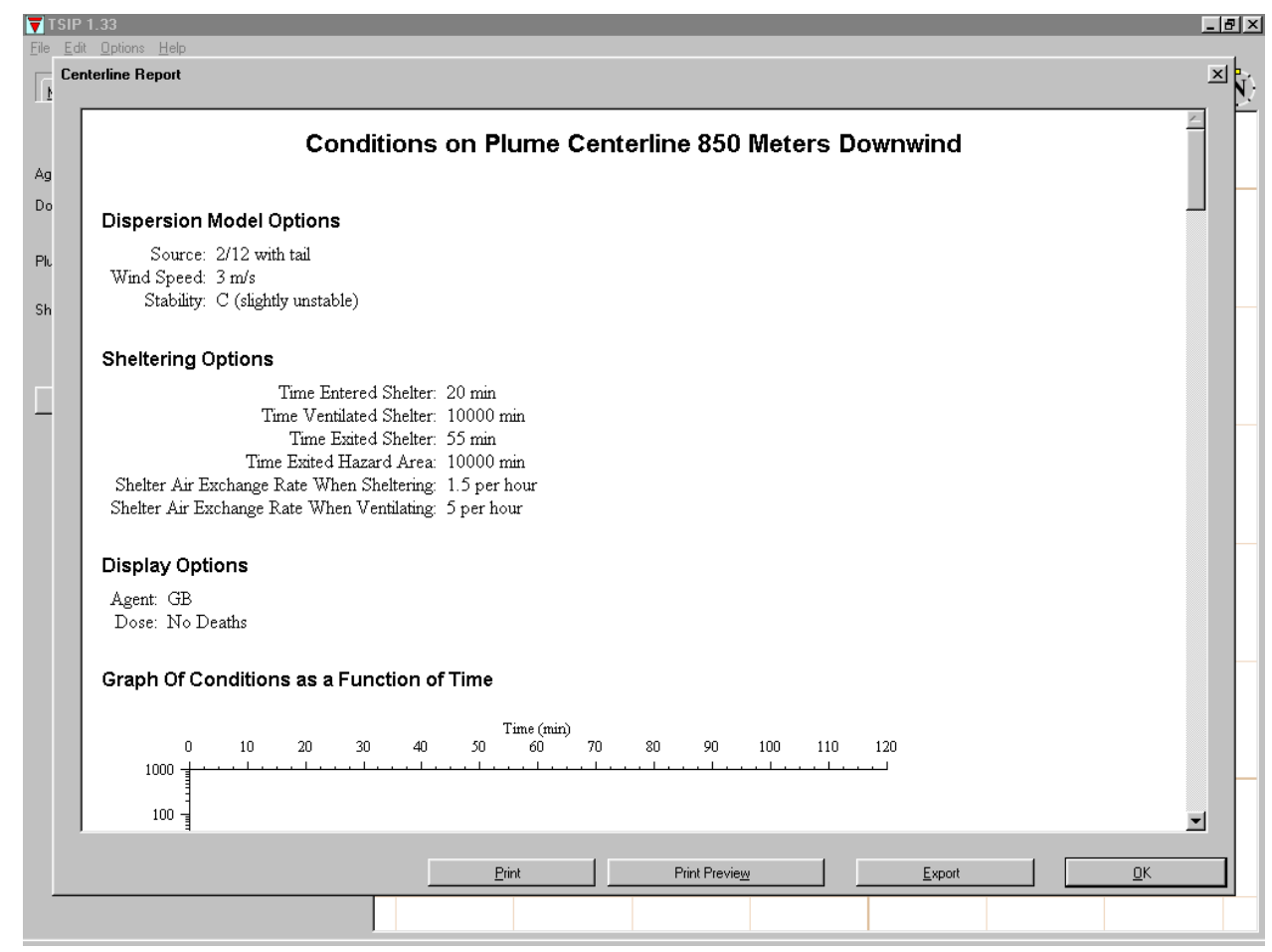

Figure 23. TSIP Display tab showing centerline report.

Next, as shown in Figure 24 on the next page, logarithmic graphs of the dose and concentration as a function of time are given. The dose as a function of time is given for the sheltering actions modeled (i.e., "actual"), along with the dose that would be received if the population was sheltered during the entire release, and the dose that would be received if the population remained outside during the entire release. The concentration as a function of time is given for both outside and inside the shelters. 


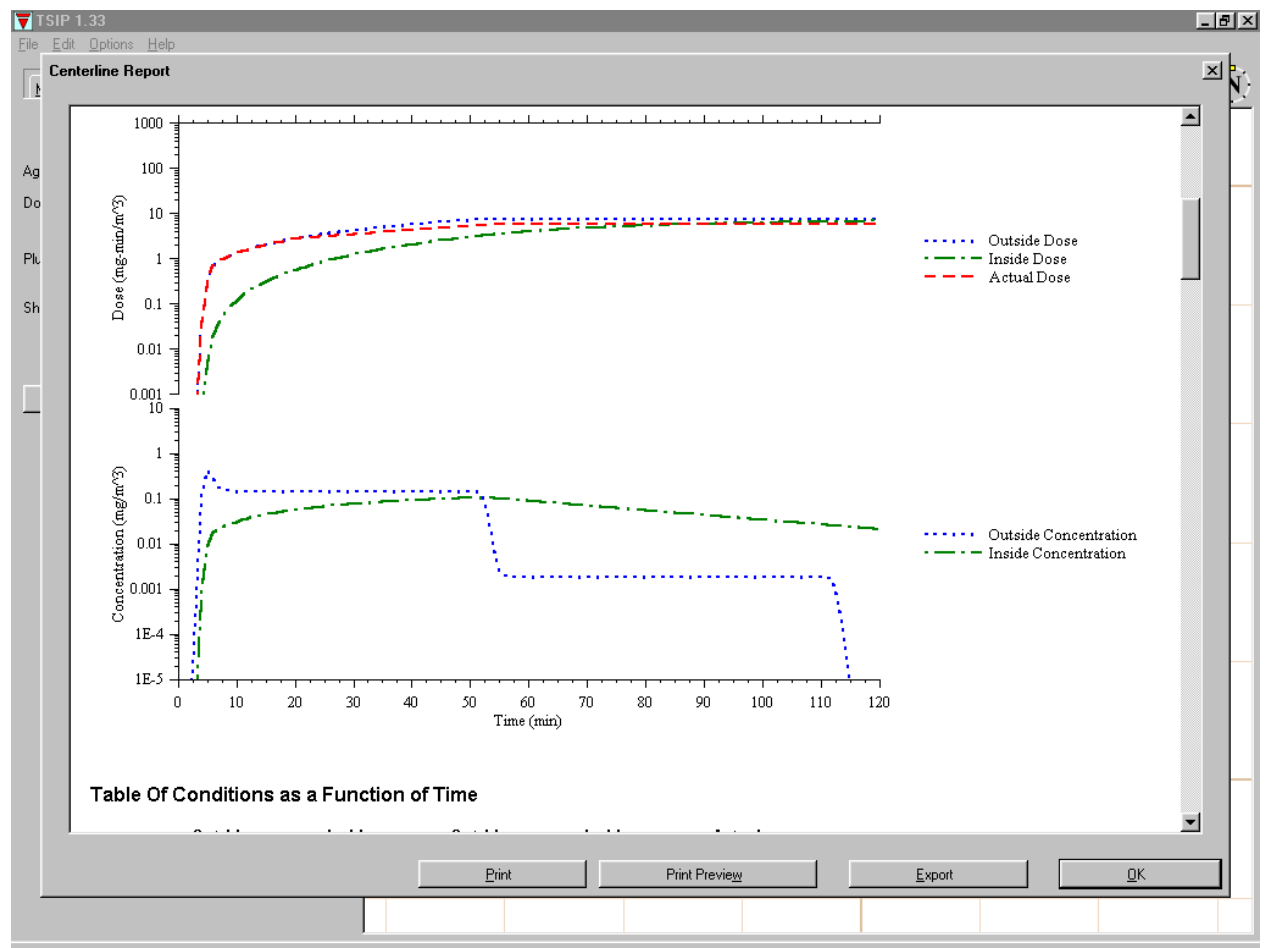

Figure 24. TSIP Display tab showing centerline report (continued).

Finally, as shown in Figure 25, a table is given that summarizes the outside and inside concentration history, the history of the cumulative doses inside and outside the shelter, and the dose for the specific sheltering actions modeled (i.e., "actual").

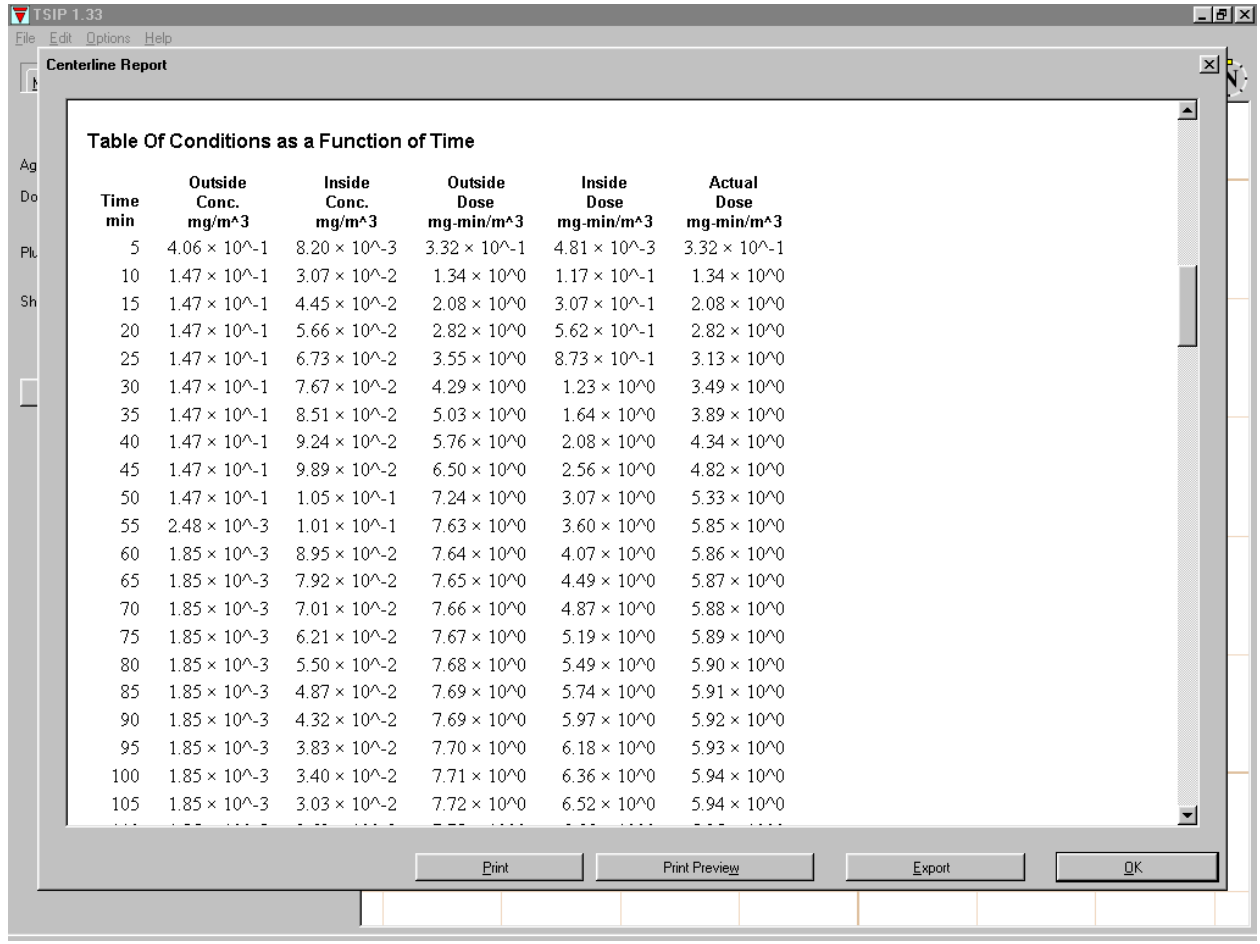

Figure 25. TSIP Display tab showing centerline report (continued). 
More detailed information about the options in the TSIP model, including all of the display and toolbar options, can be found in the menu option "Help | Show Readme File and User's Manual." The Readme File and User's Manual is also reproduced in Appendix B of this report. 


\section{APPENDIX B}

\section{INFORMATION ABOUT TSIP}

\section{TSIP Readme File and User's Manual}

This file contains important information about TSIP.

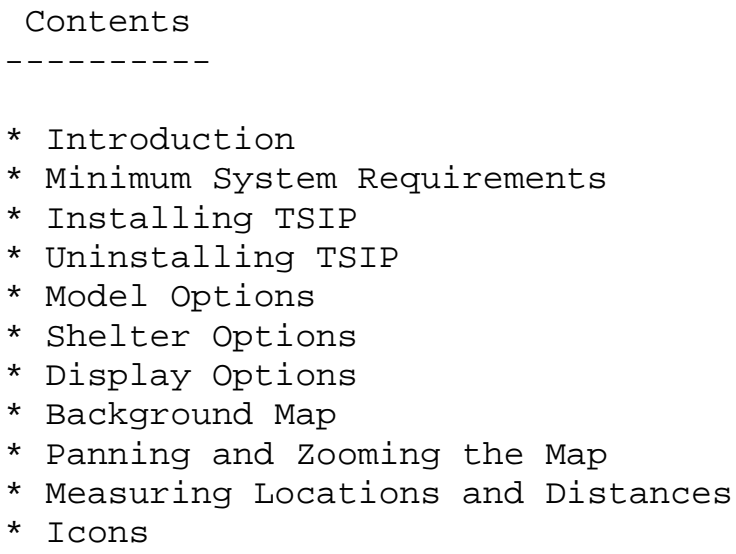

Introduction

TSIP is a utility for exploring temporary shelter-in-place strategies for protecting populations from hazardous chemical vapors.

In response to an accident involving the release of airborne hazardous material, the most intuitive strategy for protecting the surrounding population is to immediately evacuate the affected areas. However, there is often insufficient time to complete the evacuation before the plume of hazardous material reaches populated areas. In this case, an alternative protection strategy is prompt shelter-in-place: immediately sheltering in an interior room of a nearby home or building until the plume passes. Shelter-in-place is most effective if the population takes steps to make their shelters more air-tight, such as covering cracks around doors and windows with towels or tape.

Temporary shelter-in place is the combination of prompt shelter-in-place to minimize initial exposure to airborne hazardous material, followed by timely action to terminate this protection to minimize exposure to hazardous vapor accumulations in the shelter once the air outside becomes less hazardous than the air inside the shelter. Temporary SIP, if properly executed, is considered to be an effective way to protect populations from hazardous chemical vapors, especially from high concentrations for short periods. 
There are many parameters that influence the effectiveness of SIP. The most important are:

- the time-history of the vapor concentration outside the shelter

- the toxicity of the hazardous vapor

- the time at which the shelter is entered and exited

- whether the population relocates after exiting the shelter

- whether an attempt is made to ventilate the shelter after the plume passes

- the rate at which the vapor infiltrates the shelter

Using TSIP, a user can vary these parameters and explore the effectiveness of various sheltering actions. TSIP displays a map, highlighting the areas where the population is expected to receive a critical dose of the hazardous material.

The concept and methodology that this model provides can be used to determine the smallest area in the hazard wedge in which a population will suffer the toxic effect of concern (e.g., no deaths) for a given source term and meteorological conditions, based on the behavior of the population. The behavior of the population involves the time to take shelter, the time in the shelter, the protection their shelter affords, and the time needed to execute termination of SIP. The optimum time and means to terminate SIP is that which produces the smallest area for the conditions and circumstances. TSIP incorporates a basic Gaussian atmospheric dispersion model for predicting the dispersion of the chemical vapors. This model was used for simplicity to illustrate the concept and methodology. However, TSIP can be built using the CSEPP approved atmospheric dispersion models (i.e., D2PC and D2-Puff).

\section{Minimum System Requirements}

Operating System - Windows 95 or 98, Windows NT 4.0, Windows 2000

Memory - At least $64 \mathrm{MB}$

Processor - $750 \mathrm{MHz}$ Pentium III or faster recommended

Monitor - At least 64,000 colors (i.e., 16-bit color), resolution of at least $800 \times 600$

Installing TSIP

TSIP is distributed as a self-extracting Winzip file. Installation consists of nothing more than uncompressing the TSIP files and copying them onto your hard drive. To install TSIP, follow these steps...

1. Obtain the Winzip file, which is named Install_TSIP.exe.

2. From Windows Explorer or My Computer, find the file Install_TSIP.exe and double-click on it. The Installing TSIP dialog box appears.

3. In the Unzip To Folder text box, type the name of the directory where you wish to install TSIP. By default, this will be the directory c: $\backslash$ tsip. 
4. Press the Unzip button. The directory you selected is created, and the TSIP files are copied into it. TSIP is now installed.

5. The file Install_tSIP.exe is no longer needed. Delete it if you wish.

6. Run TSIP by double-clicking on TSIP.exe from Windows Explorer or My Computer.

Uninstalling TSIP

To uninstall TSIP, simply delete the directory in which the program resides. TSIP does not make any hidden changes to your computer. It does not modify the registry, and does not install any files in the Windows or system directories.

Model Options

If any of the controls in the tab labeled "Model" are changed, the dispersion model must be rerun. The button labeled "Run Dispersion Model" is enabled whenever the model needs to be rerun. It typically takes a few seconds to run.

The drop-down list control labeled Source lets you select the source to use from the library of available sources. By pressing the [+] button, you can add new sources to the library. Press the [-] button to remove a source from the library. Press the button with the picture of the hand and paper to edit a source's options.

When editing a source's mass release rate, you enter a list of emission times and mass emitted during that time. Note that the times are the length of the emission period. For example, if you entered...

$$
\begin{array}{lr}
5 & 1000 \\
15 & 0 \\
10 & 2000
\end{array}
$$

...then 1000 grams would be emitted during the first 5 minutes, the source would be off for the next 15 minutes, and then 2000 grams would be emitted during the next 10 minutes.

Shelter Options

The options in the tab of the user interface marked "Shelter" allow you to set the sheltering actions taken.

The times are measured in minutes since the start of the agent release. To animate the display, use the mouse to press and hold one of the 
up or down arrow buttons to the right of one of the time controls. The button will auto-repeat, incrementing or decrementing the time by 5 minutes.

The Shelter Air Exchange Rate controls allow you to specify the rate of air exchange between the outside and inside of the shelter. The When Shelter value is used up until the time set using the Time Ventilated Shelter control. After this time, the When Ventilating value is used.

The display will be automatically updated whenever you change any of these controls.

Display Options

Once the dispersion model has been run, you can use the controls in the "Display" tab to control how the results are displayed. The display will be automatically updated whenever you change any of these controls.

If you check the Concentration box, then both the outside and inside (meaning outside or inside a shelter) centerline concentrations will be graphically displayed along the plume centerline. Outside concentrations are indicated on the left, and inside concentrations are indicated on the right. The concentrations are indicated using a logarithmic color scale, ranging from $1 \times 10^{\wedge}-5 \mathrm{mg} / \mathrm{m}^{\wedge} 3$ (black) to $1 \times 10^{\wedge} 1 \mathrm{mg} / \mathrm{m}^{\wedge} 3$ (yellow). Use the Plume Display Time control to change the time at which the concentrations are displayed.

If you do not check the Concentration box, then a graphical representation of the plume's location will be displayed. Use the Plume Display Time control to change the time at which the plume is displayed. To hide the plume, set the Plume Display Time to zero.

If you check the Grid box, a checkerboard grid will be displayed. Major grid lines are spaced every $5 \mathrm{~km}$. Minor grid lines are spaced every $1 \mathrm{~km}$.

Pressing the Remember Wedge button will cause the currently displayed hazard wedge to be remembered on the screen. You can then change the options to cause another wedge to appear on the screen. This allows you to compare the two wedges. Press the Forget Wedge button to erase the saved wedge.

Background Map

TSIP includes a background map of the area around an Army chemical storage depot solely to enable the viewer of this utility to get an appreciation of the approximate size of a hazard wedge. It is not intended for any other purpose in this model. Users of this utility will probably find the use of grid lines to be more useful when examining the features of TSIP. 


\section{Panning and Zooming the Map}

To pan the map, either...

1. Select the Pan mouse tool (press the four-headed arrow button on the toolbar), then left-click at a position on the map. The map will pan so that position is in the center of the screen.

2. Press and hold the middle mouse button over the map, then move the mouse in any direction.

To zoom the map, either...

1. Select the Zoom mouse tool (press the magnifying glass button on the toolbar), then left-click on the map.

2. Rotate the mouse wheel over the map.

Note: When either the Pan or Zoom mouse tool is active, you can left-drag a rectangular area on the map to zoom in on that area.

Note: When either the Pan or Zoom mouse tool is active, you can right-click on the map to zoom out.

Note: If you get lost in the map, press the home button (the house button on the toolbar) to return to the map's home view.

Measuring Locations and Distances

The toolbar always shows the location of the mouse cursor, measured in kilometers east and north of the source. You can change the units used to display the location by choosing Application Options from the Options menu.

To measure a distance on the map, first press the Measurement button (the button with the ruler) on the toolbar. Then, place the mouse over a point, press and hold the left mouse button, and move the mouse to a second point. The distance between the two points will be displayed on the toolbar.

Icons

$------$

If you check the Show Icon box in the Display tab of the user interface, then the following icons will appear:

- A square with and $X$ in it will mark the location of the source. 
- If you have also checked the Concentrations box:

- A tree symbol will appear next to the outside centerline concentration indicator bar.

- A house symbol will appear next to the inside centerline concentration indicator bar. 


\section{APPENDIX C}

\section{REFERENCES}

CSEPP, 1991, Policy Paper Number 1, Definition of Maximum Protection, May.

CSEPP, 1996, Planning Guidance for the CSEPP, May 17.

CSEPP, 1999, Exercise Policy and Guidance for the CSEPP, March 19.

Federal Register, Vol. 66, No. 85. Wednesday, May 2, 2001. Notices. Environmental Protection Agency. National Advisory Committee for Acute Exposure Guideline Levels (AEGL) for Hazardous Substances; Proposed AEGL Values.

Prater, E., S. Stage, and J. Weltman, 1998, "D2-Puff Model Technical Manual," IEM/TEC98-024, IEM, November.

Rogers, G.O., A.P. Watson, J.H. Sorensen, R.D. Sharp, and S.A. Carnes, 1990, Evaluating Protective Actions for Chemical Agent Emergencies, ORNL-6615, Oak Ridge National Laboratory, Oak Ridge, Tennessee, April.

Sorensen, J. H., A. Watson, and B. Shumpert, 1995, Presentation on Shelter-In-Place as a Protective Action From Inhalation Exposure, Oak Ridge National Laboratory, Oak Ridge, Tennessee, January.

U.S. Army, 1991, Chemical Accident or Incident Response and Assistance Operations, Department of the Army Pamphlet 50-6, May 17.

Yantosik, G.D, K. Lerner, and D.M. Maloney, 2001, Temporary Shelter-In-Place as Protection Against a Release of Airborne Hazardous Material; Report of a Literature Search, Argonne National Laboratory, Argonne, Illinois, March 16 


\section{APPENDIX D}

\section{LIST OF ACRONYMS}

$\mathrm{ACH}$

AEGL

ANL

CAIRA

CSEPP

CWA

D2PCW

D2-Puff

EAS

GB

MCE

PAD

PAR

PARDOS

SIP

TAR

TSIP

VX
Air Changes per Hour

Acute Exposure Guideline Level

Argonne National Laboratory

Chemical Accident/Incident Response and Assistance

Chemical Stockpile Emergency Preparedness Program

Chemical Warfare Agent

Army computer dispersion model

Army computer dispersion model

Emergency Alert System

Non-persistent nerve agent

Maximum Credible Event

Protective Action Decision

Protective Action Recommendation

Partial Dosage (A computer program)

Shelter-in-Place (Refers primarily to normal, expedient, and enhanced shelter in this report)

Tone Alert Radio

Terminate Shelter-In-Place (Refers to an Argonne National Laboratory computer model to analyze temporary shelter-in-place strategies)

Persistent nerve agent 